Article

\title{
Predicting Heating and Cooling Loads in Energy-Efficient Buildings Using Two Hybrid Intelligent Models
}

\author{
Dieu Tien Bui ${ }^{1}{ }^{(\mathbb{D}}$, Hossein Moayedi ${ }^{2,3, * \mathbb{D}}$, Dounis Anastasios ${ }^{4}$ and Loke Kok Foong ${ }^{5}$ \\ 1 Institute of Research and Development, Duy Tan University, Da Nang 550000, Vietnam \\ 2 Department for Management of Science and Technology Development, Ton Duc Thang University, \\ Ho Chi Minh City, Vietnam \\ 3 Faculty of Civil Engineering, Ton Duc Thang University, Ho Chi Minh City, Vietnam \\ 4 Department of Industrial Design and Production Engineering, University of West Attica, \\ 12244 Egaleo, Greece \\ 5 Centre of Tropical Geoengineering (Geotropik), School of Civil Engineering, Faculty of Engineering, \\ Universiti Teknologi Malaysia, Johor Bahru 81310, Malaysia \\ * Correspondence: hossein.moayedi@tdtu.edu.vn; Tel.: +989177113193
}

Received: 7 August 2019; Accepted: 26 August 2019; Published: 29 August 2019

\begin{abstract}
Today, energy conservation is more and more stressed as great amounts of energy are being consumed for varying applications. This study aimed to evaluate the application of two robust evolutionary algorithms, namely genetic algorithm (GA) and imperialist competition algorithm (ICA) for optimizing the weights and biases of the artificial neural network (ANN) in the estimation of heating load (HL) and cooling load (CL) of the energy-efficient residential buildings. To this end, a proper dataset was provided composed of relative compactness, surface area, wall area, roof area, overall height, orientation, glazing area, glazing area distribution, as the HL and CL influential factors. The optimal structure of each model was achieved through a trial and error process and to evaluate the accuracy of the designed networks, we used three well-known accuracy criterions. As the result of applying GA and ICA, the performance error of ANN decreased respectively by $17.92 \%$ and $23.22 \%$ for the $\mathrm{HL}$, and $21.13 \%$ and $24.53 \%$ for $\mathrm{CL}$ in the training phase, and $20.84 \%$ and $23.74 \%$ for $\mathrm{HL}$, and $27.57 \%$ and $29.10 \%$ for CL in the testing phase. The mentioned results demonstrate the superiority of the ICA-ANN model compared to GA-ANN and ANN.
\end{abstract}

Keywords: heating load; cooling load; energy efficient residential buildings; artificial intelligence

\section{Introduction}

A large portion of energy (more than 30\%) is used in the building sector globally [1]. In a building, thermal energy involves two measures of cooling load (CL), and heating load (HL) [2] and these measures are regulated by heating ventilation and air conditioning (HVAC) system. The HVAC system is designed to compute the HL and CL of the space and thereby, provide a desirable indoor air condition. In this sense, some studies have focused on evaluating comfortable, yet energy-saving spaces [3]. Required cooling and heating capacities are estimated mainly according to the basic factors, including building properties, its utilization, and climate conditions. Sant'Anna et al. [4] conduct research for conventional and green buildings in terms of indoor environmental quality perception. In another research, Caniato et al. [5] studied the expectations of the thermal and acoustic performance of wooden buildings against a heavyweight structure.

Therefore, more sustainable consumption of energy can be ensured by a proper examination of the energy performance of buildings (EPB) and optimal designing of the HVAC system. Although 
many countries take such measures, there is still a high level of energy consumption, and it is projected to increase globally. A great number of scientists believe that such an increase is because of rising living standards. For example, building construction in Europe must meet special conditions related to energy efficiency. It should be noted that $40 \%$ of energy in Europe is consumed in buildings [6]. According to reports, this value approximately comprises $39 \%$ of the total primary energy requirement (PER) and 27.5\% of total national energy use in the United States [7] and China [8], respectively.

According to the items mentioned above, many engineers have tried to develop different predictive and evaluative tools the primary aim in order to produce an optimal approximation of building energy consumption. So far, building energy has been modelled in a number of attempts $[9,10]$. Generally, there are two common methods for EPB evaluation: Forward modelling and inverse modelling [11]. In former, the tools are used to simulate the energy performance by taking into account the actual attributes of the building (e.g., geometry). Since the application of such simulators involves control over certain parameters that are difficult to be set in practice, there are some related disadvantages. However, the chief problem in forwarding modelling is that it is not suited to appraising the EPB of the occupied buildings [12]. In addition, this method is time-consuming and requires a lot of precision as it involves a large number of parameters. Moreover, employing various simulation programs can yield estimations with varying accuracies [13]. Nonetheless, these programs could be reliable in evaluating the effects of a single parameter on EPB when other parameters remain unchanged. Designer's Simulation Toolkit (DeST) [14], Energy Plus [15], DOE-2 [16] are among the well-known computer software tools used in this subject.

To assess EPB, many researchers have turned to the inverse (data-driven) modelling [17] in order to avoid the drawbacks of the simulation packages. In this sense, if a sufficient number of instances (consisting of some inputs and targets) are available, it is viable to evaluate the impact of influential factors (e.g., relative compactness, roof area, and orientation) on EPB $[18,19]$. The chief advantage in using artificial intelligence (AI) is its high-performance speed, as well as the ease of implementation. Moreover, the optimal structure of machine learning methods can easily handle the changes in variables (changing in the building design parameters, in this case) that is a formidable challenge for designers and architectures alike. In what follows, an extensive report is presented in the previous attempts that investigated the feasibility of various AI techniques in EPB. Notably, although AI techniques have been effectively used in estimating and optimization of the energy performance of buildings, few researchers have focused on enhancing the effectiveness of the typical predictive models. Hence, the focal effort of the current research is to design two metaheuristic algorithms to improve the quality of the estimation of the artificial neural networks in the field of HL and CL of the residential buildings. To do this, after providing the suitable dataset, an extensive trial and error process was executed to achieve the optimal structure of the proposed models namely, multi-layer perceptron (MLP) neural network, the combination of artificial neural network (ANN) and genetic algorithm (GA-ANN), and the combination of ANN and imperialists competition algorithm (ICA-ANN).

\section{Literature Review}

Similar to many other fields of research, AI techniques have attracted great attention in building energy consumption evaluation. Among various types of AI techniques, artificial neural network (ANN) is a well-known technique that is widely employed for many simulation problems [20,21]. Moreover, ANN has emerged as an effective tool in building energy management [22,23]. Mejías et al. [24] used linear regression models and artificial neural networks to estimate three concepts of heating and cooling energy demands, energy consumptions and $\mathrm{CO}_{2}$ emissions in office buildings. They discovered that the ANN system could perform better than other models as it yields results with greater accuracy. Deb et al. [25] investigated ANN capability in forecasting the diurnal cooling energy load and found that ANN can successfully predict daily energy use by taking into account the records of five previous days. In addition, Li et al. [26] conducted a comparative study that focused on the estimation of an hourly cooling load of the building. Their study compared support vector 
machine (SVM) against three common types of neural networks: Traditional backpropagation neural network (BPNN), general regression neural network (GRNN), and radial basis function neural network (RBFNN). They found that SVM and GRNN could offer better prediction than the RBNN and RBFNN predictive tools, based on the root mean square error (RMSE) and mean relative error (MRE). In addition to ANN, many other methods have been used in dealing with energy-efficient residential buildings problem. For instance, Yun et al. [27] effectively used an indexed ARX regression model in order to forecast the thermal load of building on an hourly basis. In a case study, by Yao et al. [28] examined the ability of a combined forecasting model based on the analytic hierarchy process (AHP) in appraising the hourly cooling load. They showed that combined models could outperform individual ones. In addition, some studies have investigated the efficiency of SVMs regarding the same objectives. Dong et al. [29] evaluated the SVM regression method in approximating building energy consumption in case of a tropical region. Their results show that this model is reliable enough based on the calculated coefficients of variance (CV) (less than 3\%) and a small percentage error (4\%). Jing and Xiaojuan [30] modelled the dynamic cooling and heating load of an office building by developing a hybrid method based on wavelet transform, SVM, and partial least squares regression (PLS) to. Accordingly, they chose a building located in Tianjin, China. A multiple-horizon prediction was performed after they carried out a sensitivity analysis for selecting the best inputs combination. According to their results, the developed model can be used to identify an accurate perception of the problem. Li et al. [31] synthesized an adaptive neuro-fuzzy inference system (ANFIS) with a genetic algorithm in order to improve its accuracy in estimating building energy consumption. They found that this synthesis not only does provide a reliable model, but also gives better performance than does the ANN model. In addition, Random forest (RF) model has been applied for the quantitative prediction of energy performance [32]. Similarly, multiple linear regression can yield a correlation coefficient of 0.987 for evaluation of the heating energy demand [33].

Hereafter, four general sections form the body of this research. Explanations about the considered models are available in Section 3. Section 4 is devoted to data preparation, and statistically analysis of them. Following this, the outcomes are presented and discussed in Section 5. Eventually, Section 6 is the conclusion giving a brief report of the current research.

\section{Description of the Used Models}

\subsection{Multi-Layer Perceptron (MLP)}

The idea of an artificial neural network (ANN) was first suggested in 1943 by McCulloch and Pitts [34]. Originally, ANNs are inspired by the human neural network and has been satisfactorily used for several fields of research $[35,36]$. The main advantage of this model lies in the ability of mapping the non-linear relationship between sets of input-output pairs. Among various kinds of ANNs, multi-layer perceptron (MLP) is a reliable tool which is designed for the case of this study to predict the HL and CL of the residential buildings. As is shown in Figure 1, an MLP is composed of three layers that each layer contains a number of computational units (i.e., neurons). During the MLP performance, it has been aimed to find the optimal values of weights $(\mathrm{W})$ and biases (b) to obtain the best accommodation between the targets and outputs of the system. More specifically, let $\mathrm{T}$ be the input vectors; then, the output of the $\mathrm{k}$-th neuron is calculated as follows:

$$
Y_{k}=F\left(\sum_{m=1}^{z} T_{m} W_{m k}+b_{k}\right),
$$

where $T$ denotes the input value, $W$ and $b$ are the assigned weight and bias, respectively. Also, the term $F$ symbolizes the activation function. 


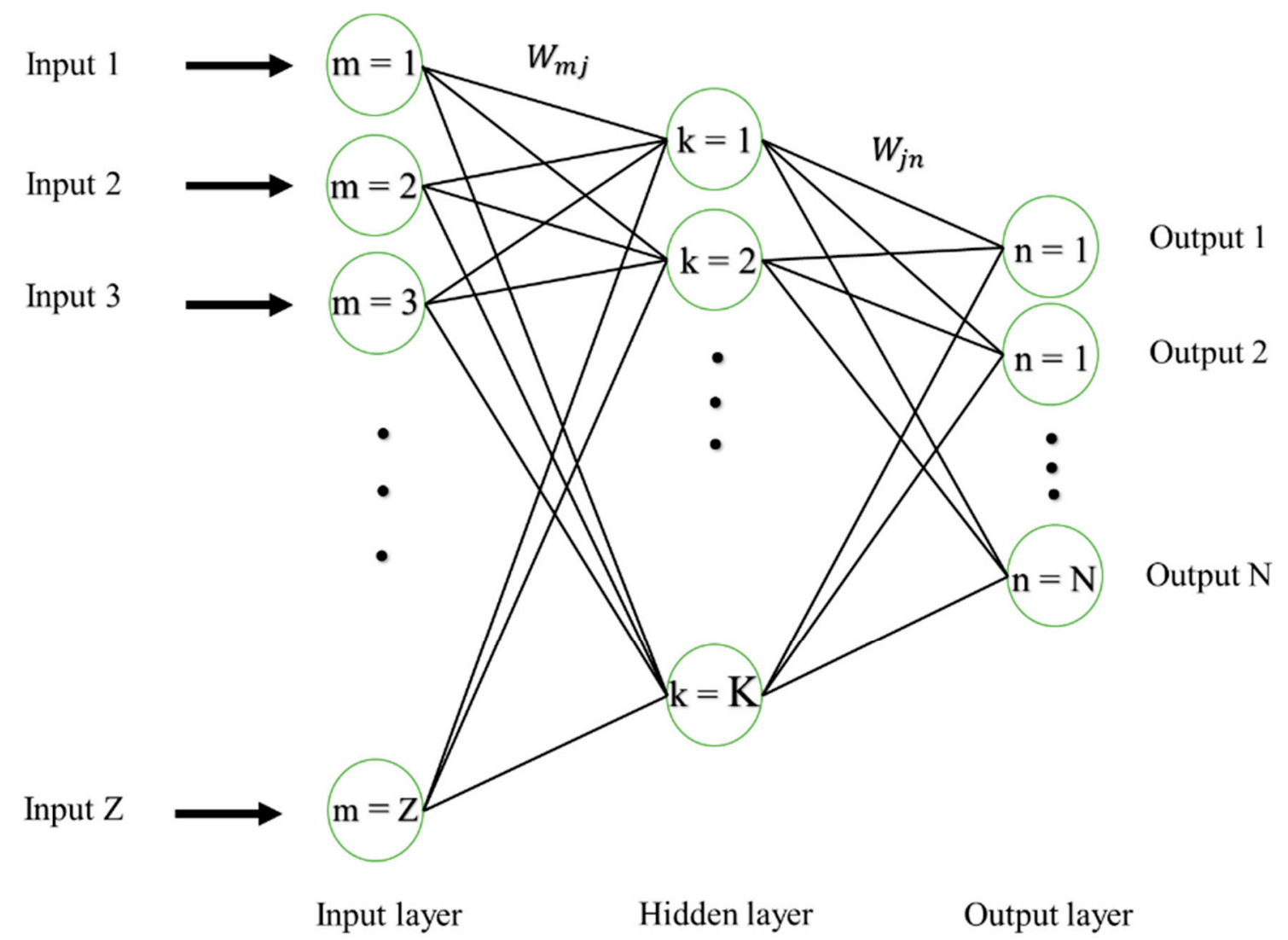

Figure 1. The general structure of the multi-layer perceptron (MLP) network.

\subsection{Genetic Algorithm (GA)}

Inspired by the theory of natural selection, Genetic algorithm (GA) was first presented by Holland [37]. GA is one of the most effective evolutionary computing which one of its aims is to improve the applicability of various networks, ANNs for example. Dealing with highly non-linear and intricate problems can be mentioned as the excellence of GA. Accordingly, for most modelling aims, there are various conditions that can be well handled by GA. Geotechnical simulations are a good instance of such cases, associated with changes in loading condition (dynamic and static loading patterns), continuous or discontinuous soil media, and linear or nonlinear soil behaviors. Due to different parameters that must be optimized for achieving a proper GA, it can be categorized as a problematic optimization algorithm (OA).

As stated supra, GA is a heuristic search technique that follows the natural selection rules to provide an effective solution. GA is a well-known component of a larger group of evolutionary algorithms (EA) that perform based on natural evolution techniques suchlike crossover, mutation, selection, and inheritance [38]. In the commencing of GA performance, some so-called solutions "population" are involved. In this procedure, new populations (offspring) are generated by existing relations. The fitness of each chromosome is evaluated to select two parent chromosomes from the population. It is notable that this determines the chance of relations to reproduce. In other words, the more fitness they have, the more likely to reproduce. This process continues until one of the stopping criteria (improvement of the best solution or number of populations) is met. Figure 2 illustrates a graphical view of the mentioned process. 


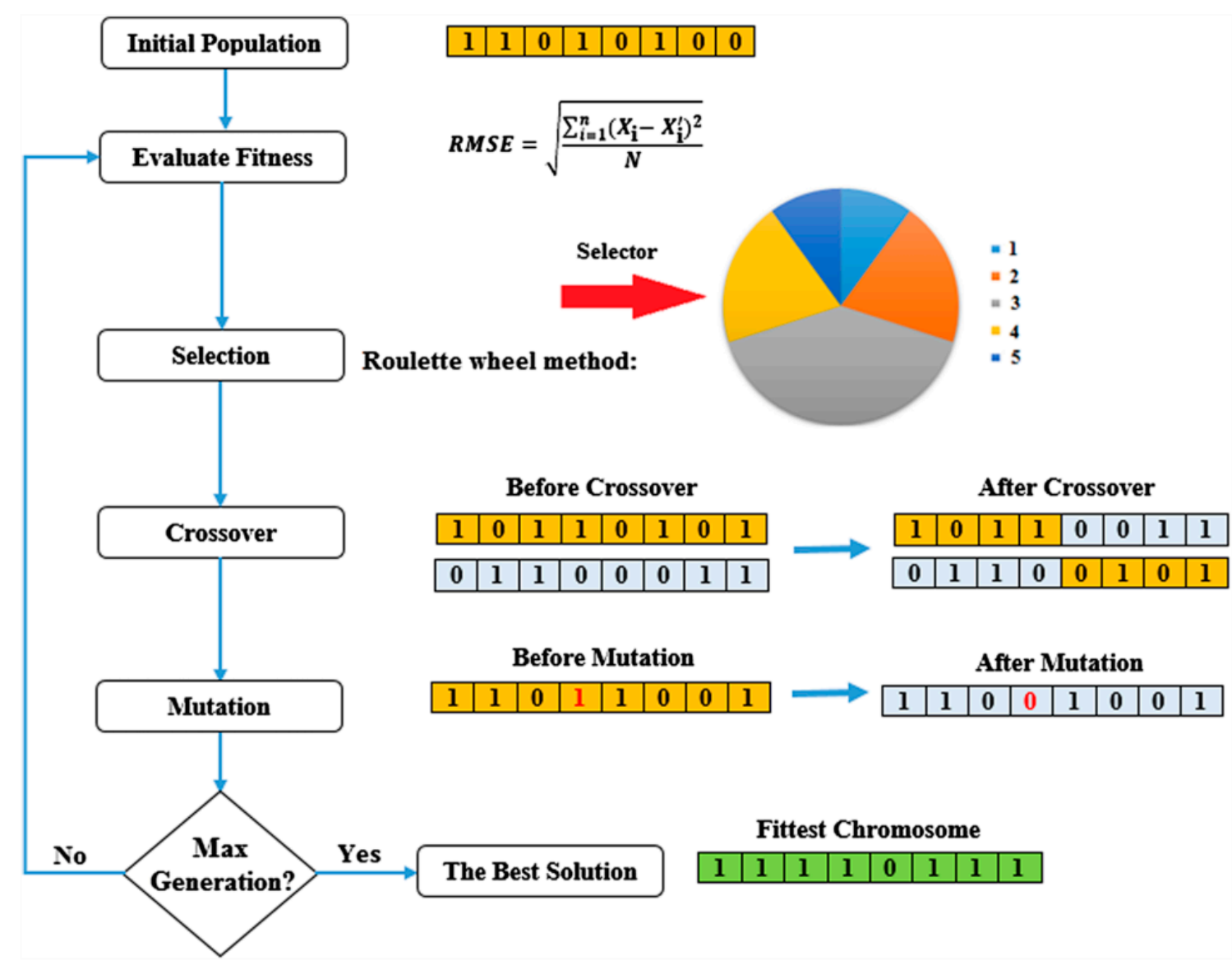

Figure 2. The main flowchart of the genetic algorithm (after Reference [39]).

\subsection{Imperialist Competitive Algorithm (ICA)}

Imperialist Competitive Algorithm (ICA) is a newly-developed metaheuristic algorithm. Inspired by the socio-political process of imperialism and imperialistic competition, this model was first suggested by Atashpaz-Gargari and Lucas in 2007 [40]. ICA capability in dealing with various optimization issues has been evaluated thoroughly in the literature [41]. Similar to other evolutionary techniques (e.g., particle swarm optimization and genetic algorithm) ICA is a population-based system which gets started with a user-defined population (i.e., the number of countries). As Figure 3 displays, two major groups of countries form the so-called units "empire." The first group is known as Imperialists comprising a number of the elite countries, and the remaining countries are defined as the Colonies. During the ICA implementation, imperialists aim to extend their territories to the governing colonies. Since this procedure is an uncontrolled action, we may witness a revolution in each country. Note that, every country can define its self in a new empire initial other than the initial one. The tendency of the countries for the higher chance promotion can be mentioned as the main reason for this. The result of the mentioned steps is that the possession of the weaker colonies is taken by, the stronger one. This process continues until a predetermined stopping criterion is met. More details about the ICA mechanism is well-explained in other researches [42]. 


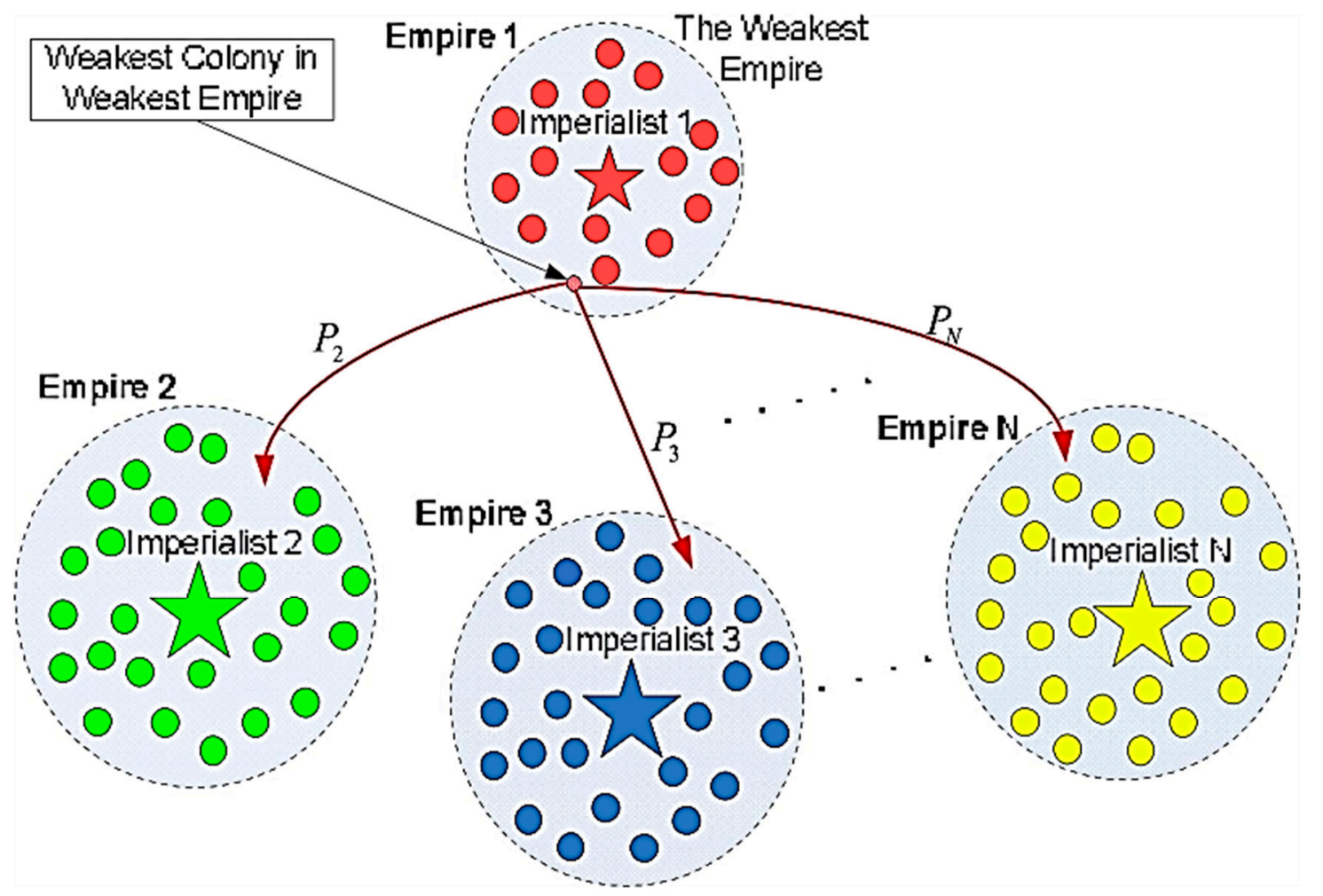

Figure 3. Taking possession of the weakest colony during the imperialistic competition (after Reference [42]).

\section{Data Preparation and Statistics}

In this study, we used the dataset taken from https://cml.ics.uci.edu/, based on research by Tsanas and Xifara [32]. Eight input parameters, including relative compactness, surface area, wall area, roof area, overall height, orientation, glazing area, and glazing area distribution of a residential building, (named as $\mathrm{X} 1, \mathrm{X} 2, \ldots, \mathrm{X} 8$, respectively) and two response parameters, including heating load (HL) and cooling load (CL) (named as Y1 and Y2, respectively) of the proposed building construct the mentioned dataset. Figure 4 shows a graphical description from data preparation procedure. Considering twelve different buildings, four glazing areas, five distribution scenarios, and four orientations, 768 buildings were modelled and analyzed by using Ecotect computer software [43]. The basic assumptions and the characteristics of the considered building are well described in Reference [32]. Additionally, Table 1 denotes the results of the statistical analysis of both independent and dependent variables.

To better understand the issue, the relationship between the inputs and output variables is demonstrated in this section. To do so, the 3D distribution of each independent parameter (i.e., input variables) against both response variables is depicted in Figure 5. In this regard, each diagram shows the $\mathrm{X} 1, \mathrm{X} 2, \ldots, \mathrm{X} 8$ on the $\mathrm{x}$-axis, versus $\mathrm{Y} 1$ and $\mathrm{Y} 2$ on the $\mathrm{y}$ and $\mathrm{z}$ axes. 
12 buildings

(different surface area and dimensions)

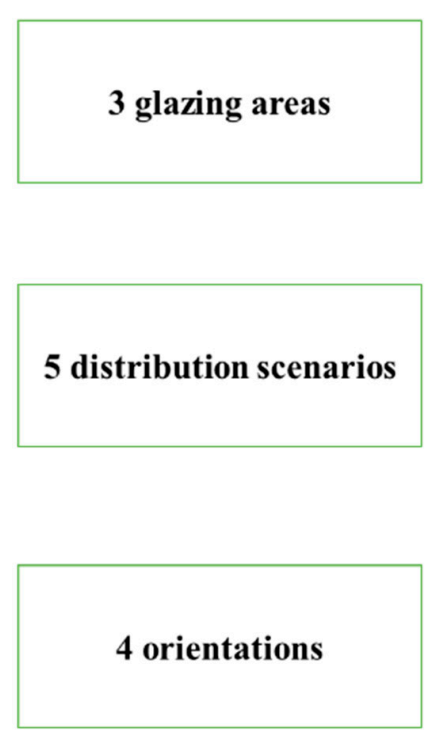

Provided dataset

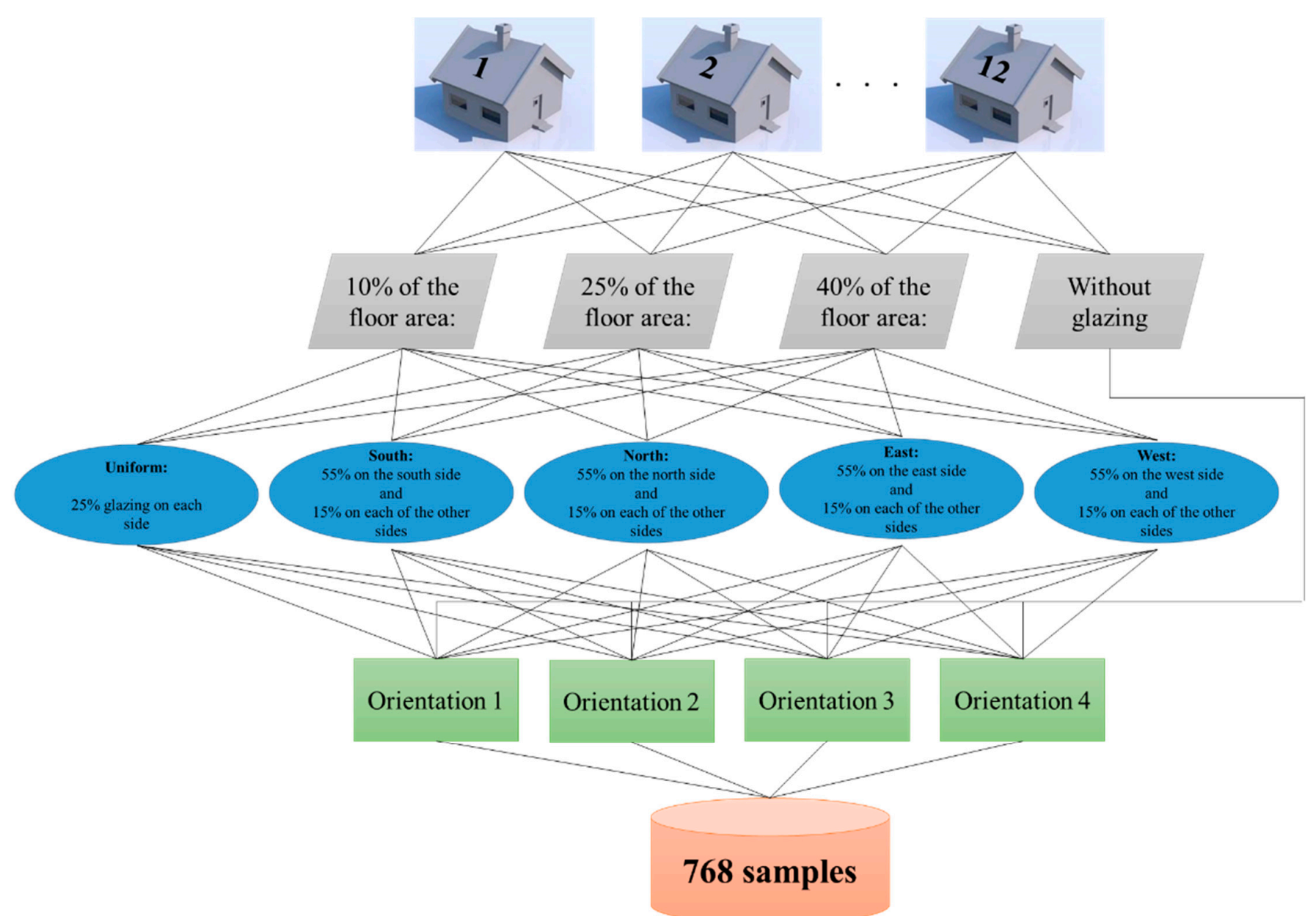

Figure 4. Graphical view of data preparation. 
Table 1. Statistical analysis of energy-efficient design on ten features of the efficient building

\begin{tabular}{|c|c|c|c|c|c|c|c|c|c|c|c|c|}
\hline \multirow[b]{2}{*}{ Features } & \multirow{2}{*}{$\begin{array}{l}\text { No. of Possible } \\
\text { Values }\end{array}$} & \multirow[b]{2}{*}{ Label } & \multicolumn{10}{|c|}{ Descriptive Index } \\
\hline & & & Mean & $\begin{array}{l}\text { Standard } \\
\text { Error }\end{array}$ & Median & Mode & $\begin{array}{l}\text { Standard } \\
\text { Deviation }\end{array}$ & $\begin{array}{l}\text { Sample } \\
\text { Variance }\end{array}$ & Skewness & Minimum & Maximum & Count \\
\hline $\begin{array}{c}\text { Relative } \\
\text { Compactness }\end{array}$ & 12 & $\mathrm{X} 1$ & 0.76 & 0.00 & 0.75 & 0.98 & 0.11 & 0.01 & 0.50 & 0.62 & 0.98 & 768 \\
\hline Surface Area & 12 & $\mathrm{X} 2$ & 671.71 & 3.18 & 673.75 & 514.50 & 88.09 & 7759.16 & -0.13 & 514.50 & 808.50 & 768 \\
\hline Wall Area & 7 & $\mathrm{X} 3$ & 318.50 & 1.57 & 318.50 & 294.00 & 43.63 & 1903.27 & 0.53 & 245.00 & 416.50 & 768 \\
\hline Roof Area & 4 & $\mathrm{X} 4$ & 176.60 & 1.63 & 183.75 & 220.50 & 45.17 & 2039.96 & -0.16 & 110.25 & 220.50 & 768 \\
\hline Overall Height & 2 & $X 5$ & 5.25 & 0.06 & 5.25 & 7.00 & 1.75 & 3.07 & 0.00 & 3.50 & 7.00 & 768 \\
\hline Orientation & 4 & $\mathrm{X} 6$ & 3.50 & 0.04 & 3.50 & 2.00 & 1.12 & 1.25 & 0.00 & 2.00 & 5.00 & 768 \\
\hline Glazing Area & 4 & $\mathrm{X} 7$ & 0.23 & 0.00 & 0.25 & 0.10 & 0.13 & 0.02 & -0.06 & 0.00 & 0.40 & 768 \\
\hline $\begin{array}{l}\text { Glazing Area } \\
\text { distribution }\end{array}$ & 6 & $\mathrm{X} 8$ & 2.81 & 0.06 & 3.00 & 1.00 & 1.55 & 2.41 & -0.09 & 0.00 & 5.00 & 768 \\
\hline Heating load & 586 & Y1 & 22.31 & 0.36 & 18.95 & 15.16 & 10.09 & 101.81 & 0.36 & 6.01 & 43.10 & 768 \\
\hline Cooling load & 636 & $\mathrm{Y} 2$ & 24.59 & 0.34 & 22.08 & 21.33 & 9.51 & 90.50 & 0.40 & 10.90 & 48.03 & 768 \\
\hline
\end{tabular}




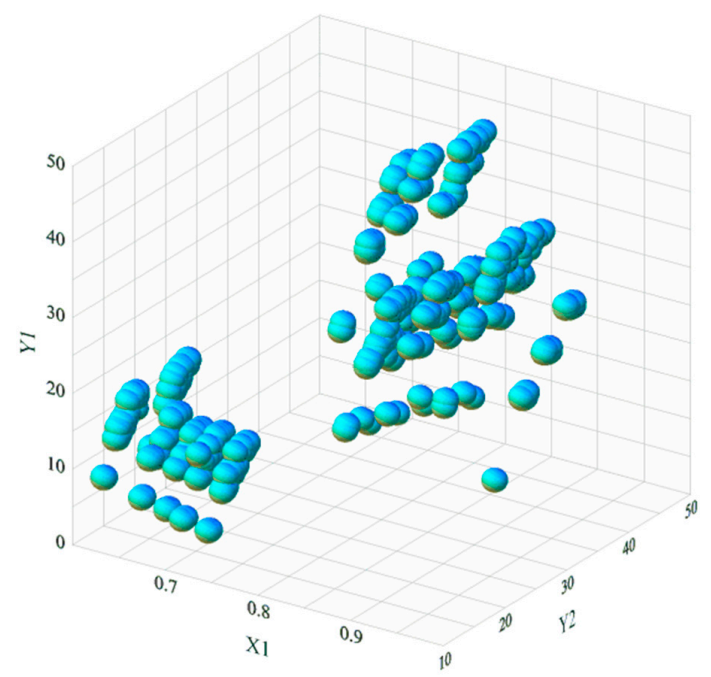

(a)

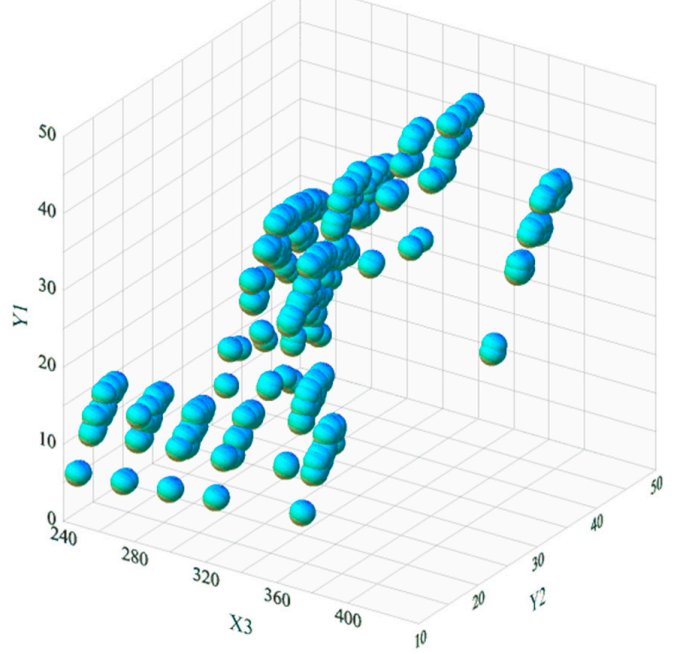

(c)

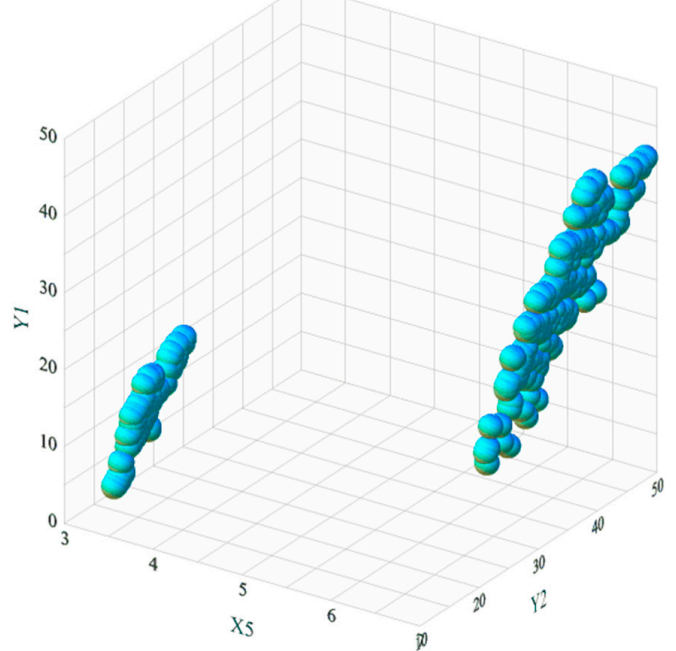

(e)

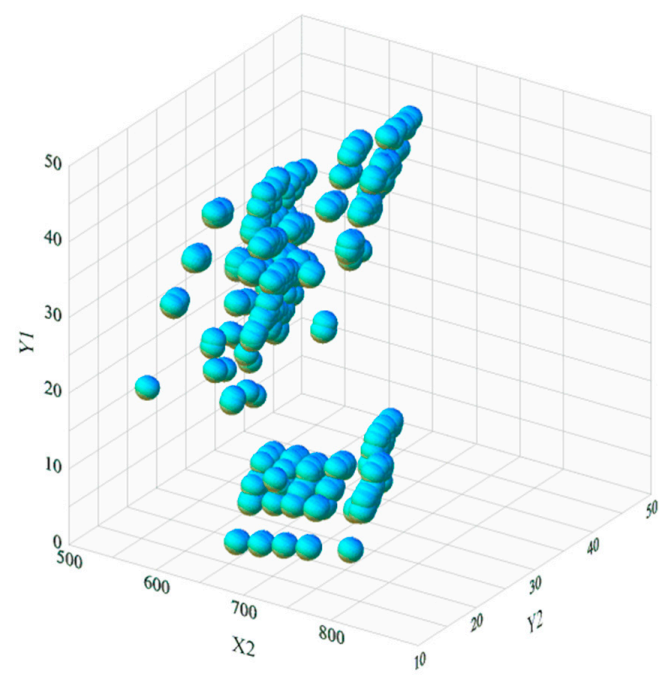

(b)

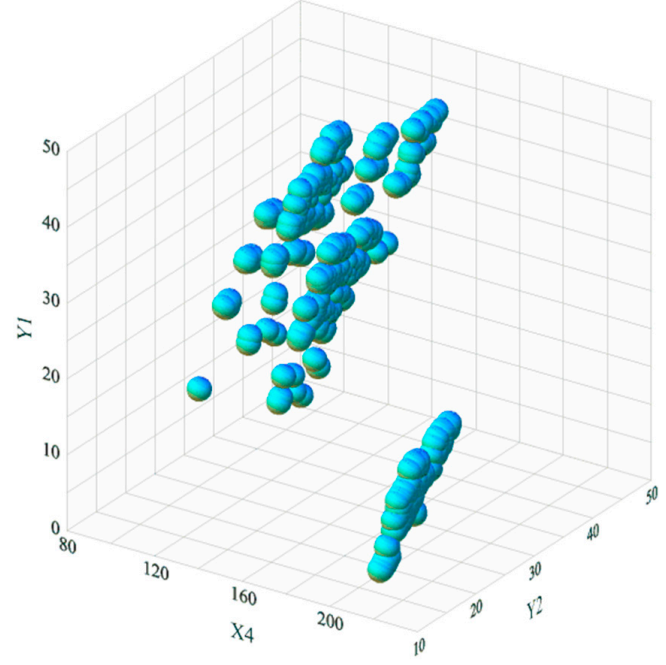

(d)

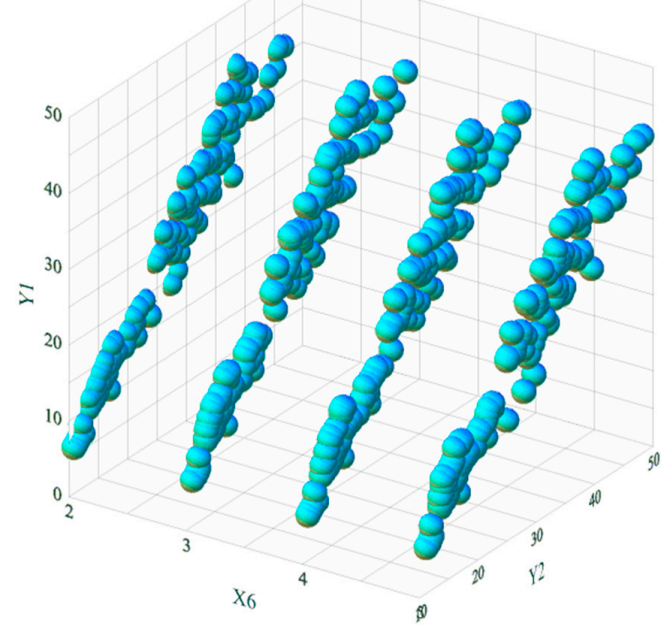

(f)

Figure 5. Cont. 


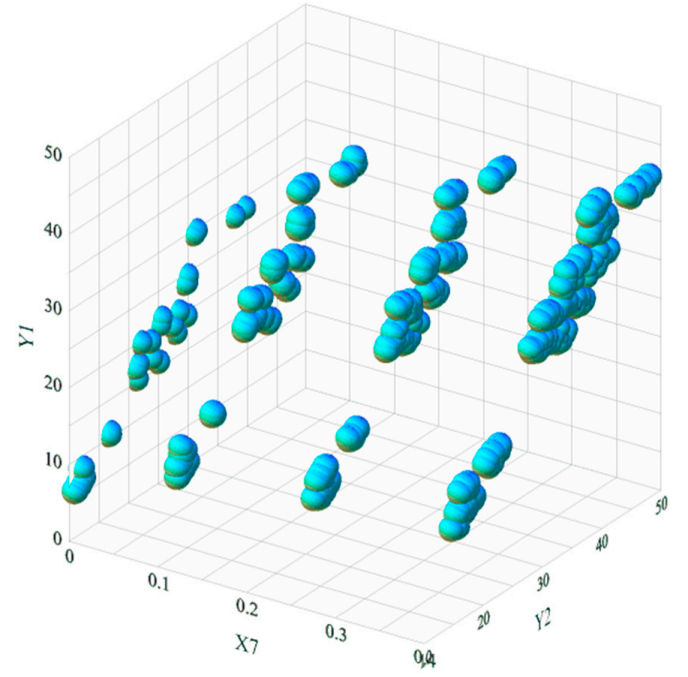

(g)

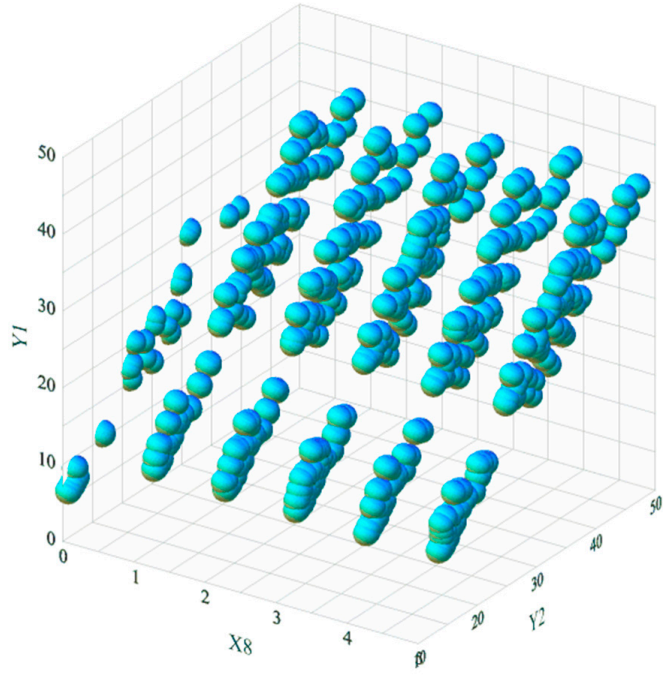

(h)

Figure 5. The spatial distribution of the $\mathrm{X} 1$ (a), $\mathrm{X} 2$ (b), X3 (c), X4 (d), X5 (e), X6 (f), X7 (g), X8 (h), against the heating load (HL) and cooling load (CL).

Moreover, the frequency of output data has been calculated and depicted in the form of histogram charts by using IBM SPSS software. These diagrams are available in Figure 6a,b. Furthermore, according to the Figure $6 c$, the high correlation between the values of $Y 1$ and $Y 2\left(R^{2}=0.9523\right)$ portends a meaningful accommodation between these two variables. It shows that HL is positively correlated with CL. In other words, the input samples that produce low/high values of $\mathrm{HL}$, give low/high values of $\mathrm{CL}$, too.

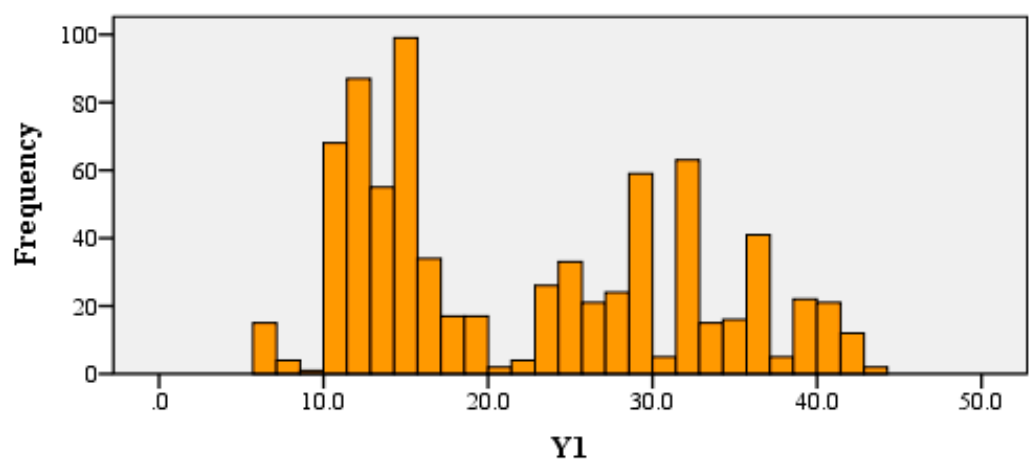

(a)

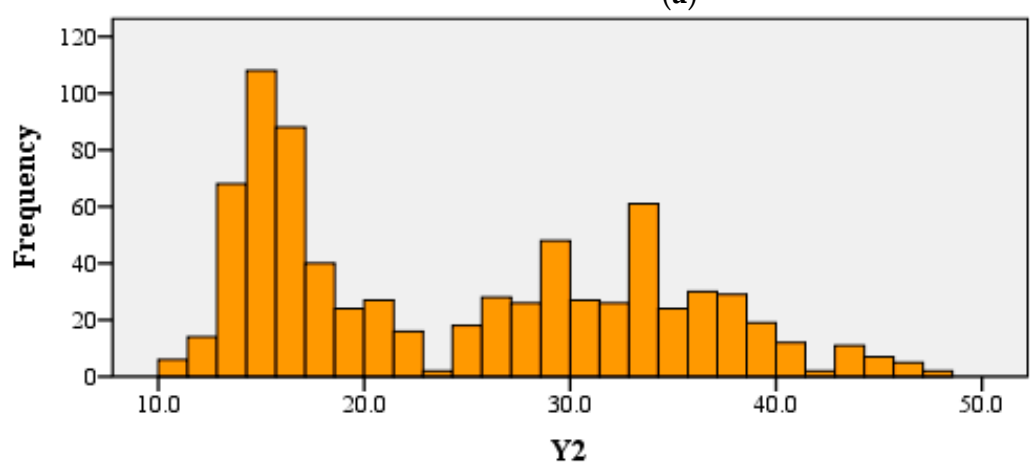

(b)
Mean $=22.307$

Std. Dev. $=10.090$
Mean $=24.59$

Std. Dev. $=9.513$

Figure 6. Cont. 


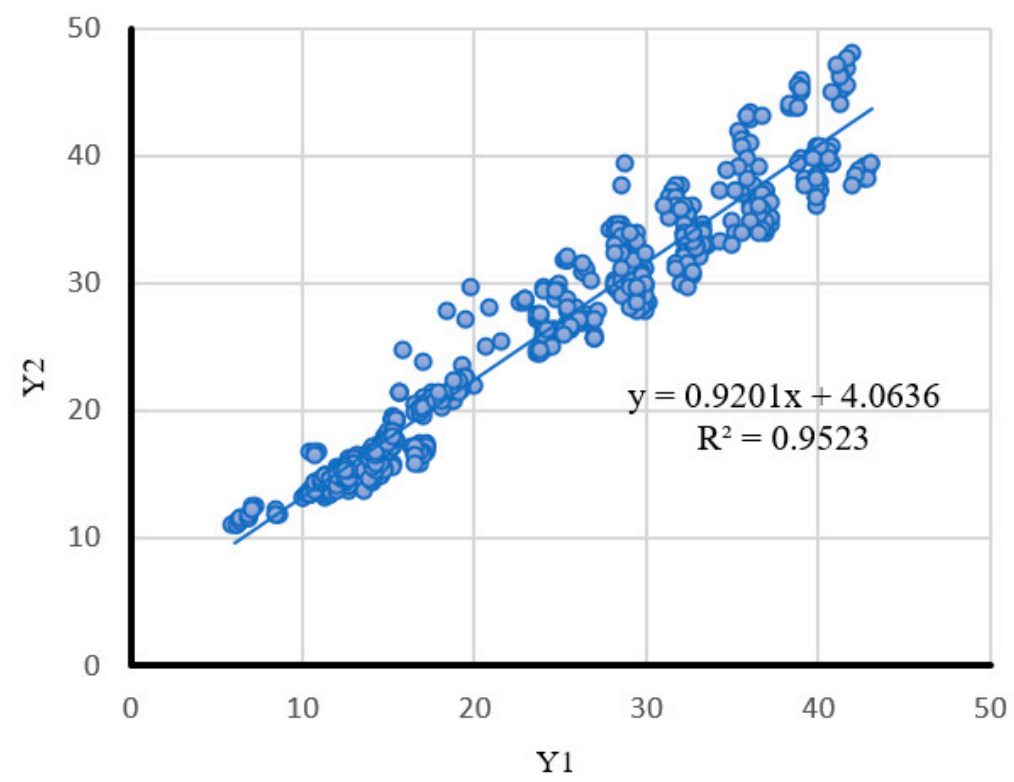

(c)

Figure 6. The histogram of the $\mathrm{Y} 1$ (a) and $\mathrm{Y} 2$ (b) and the correlation (c) between them.

\section{Results and Discussion}

This study addresses the application of two optimization algorithms of genetic algorithm (GA) and imperialist competition algorithm (ICA) for improving the performance of the artificial neural network (ANN) for modeling the heating load (HL) and cooling load (CL) of a residential building. Note that, the mentioned algorithms are employed to find the best computational parameters (i.e., the weights and biases) of the ANN. Eight influential factors, including relative compactness, surface area, wall area, roof area, overall height, orientation, glazing area, and glazing area distribution of a residential building were selected to form the input dataset. Among 768 samples, $80 \%$ (614 records) were randomly selected and devoted to the training phase, and the remaining $20 \%$ (154 records) were used to evaluate the accuracy of ANN, GA-ANN, and ICA-ANN models. In this sense, to evaluate and compare the efficiency of the applied models, three accuracy criterions namely, $R^{2}$, MAE, RMSE were defined, which have been extensively used in earlier studies [44,45]. Equations (2)-(4) formulate the mentioned statistical indices.

$$
\begin{gathered}
R^{2}=1-\frac{\sum_{i=1}^{N}\left(Y_{i_{\text {observed }}}-Y_{i_{\text {predicted }}}\right)^{2}}{\sum_{i=1}^{N}\left(Y_{i_{\text {observed }}}-\bar{Y}_{\text {observed }}\right)^{2}} \\
M A E=\frac{1}{N} \sum_{i=1}^{N}\left|Y_{i_{\text {observed }}}-Y_{i_{\text {predicted }} \mid}\right| \\
\text { RMSE }=\sqrt{\frac{1}{N} \sum_{i=1}^{N}\left(Y_{i_{\text {observed }}}-Y_{i_{\text {predicted }}}\right)^{2},}
\end{gathered}
$$

where $Y_{i \text { observed, }}$ and $Y_{i \text { predicted }}$ denote the actual and predicted values of HL (or CL) of the efficient building, respectively. The term $\mathrm{N}$ represents the number of instances, and $\bar{Y}_{\text {observed }}$ stands for the average of the actual values of $\mathrm{HL}$ (or CL). 


\subsection{Finding the Optimal Structure of the Intelligent Models}

As is known, determining an optimal structure of the networks is a substantial step in the field of artificial intelligence utilization. In this study, we executed an extensive trial and error process to achieve the appropriate architecture of ANN, GA-ANN, and ICA-ANN models. To do this, mean square error (MSE) was defined as the objective function to measure the accuracy of various structures of the networks. MSE is expressed as follows:

$$
M S E=\frac{1}{N} \sum_{i=1}^{N}\left(Y_{i_{o b s e r v e d}}-Y_{i_{\text {predicted }}}\right)^{2}
$$

where similar to the aforementioned criteria, $N, Y_{i \text { observed, }}$, and $Y_{i \text { predicted }}$ respectively symbolize the number of samples, actual and predicted values of HL (or CL).

For ANN, a feed-forward back-propagation MLP containing one hidden layer was tasted based on different numbers of hidden neurons. Also, the Levenberg-Marquardt (LM) training algorithm is applied, due to the better performance compared to conventional gradient descent (GD) technique [46,47]. Besides, the tangent-sigmoid activation function (simply called Tansig) was used in this study, which is formulated as follows:

$$
\operatorname{Tansig}(x)=\frac{2}{1+e^{-2 x}}-1
$$

Figure 7 depicts the results of the sensitivity analysis carried out to select the best ANN structure, as is shown. However, the MLP with 3, 4, and 5 nodes in its hidden layer yields a satisfying approximation, and the least MSE is obtained by the network with four hidden neurons. So, the used ANN model forms as $8 \times 4 \times 2$ representing eight input neurons, four hidden neurons, and two output neurons, respectively. This is noteworthy that this structure was used in the following and for the GA-ANN and ICA-ANN predictive models.

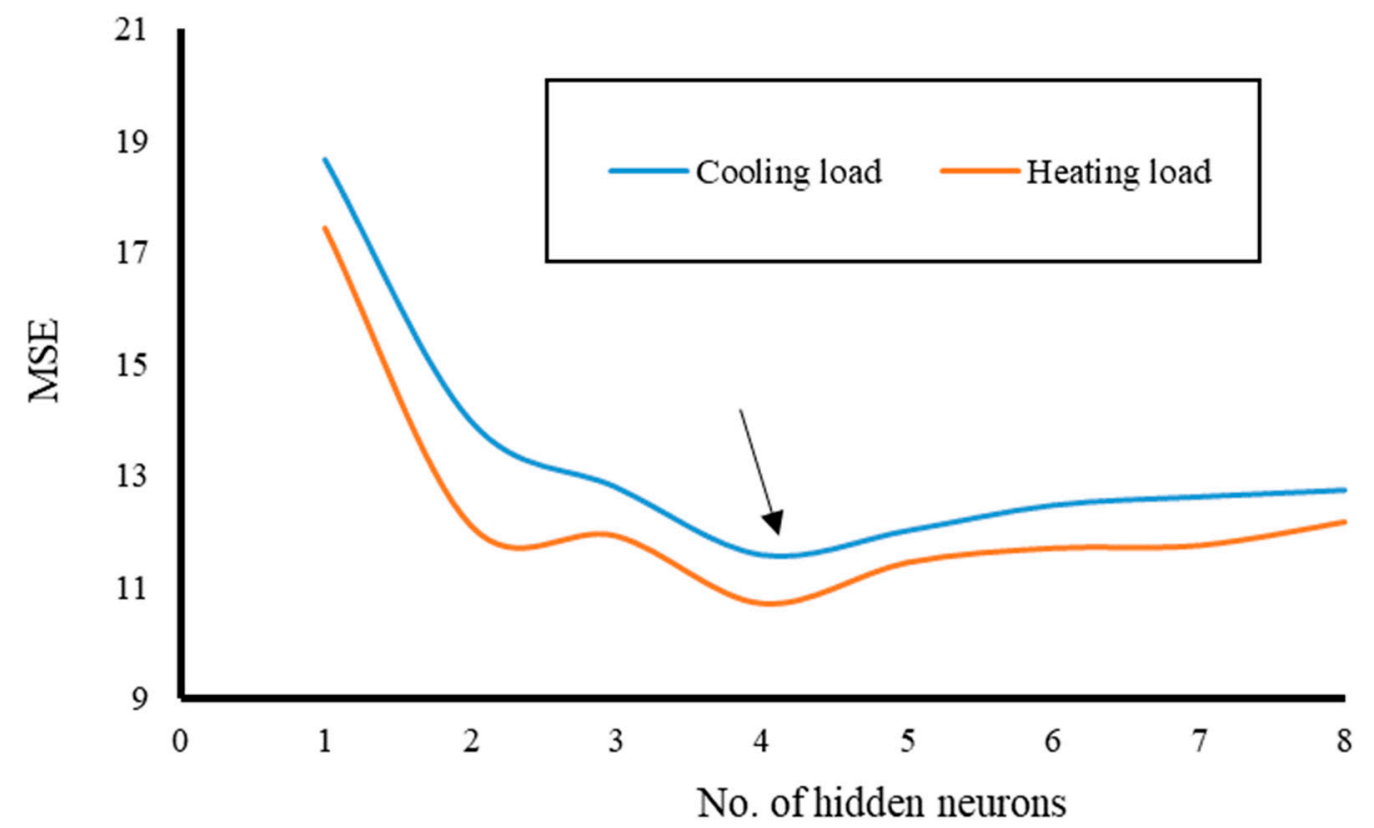

Figure 7. A sensitivity analysis for artificial neural network (ANN), based on the number of hidden neurons.

As explained supra, to enhance the capability of the typical ANN, we combined it with genetic algorithm and imperialist competition algorithm (Figure 8). Similar to ANN, the best parameters were 
selected via a trial and error process. There are several parameters that affect the learning process of evolutionary algorithms. In the case of this study, different population sizes for GA, and a different number of decades for ICA were tested within 1000 iterations. Moreover, similar to Koopialipoor et al. [39], the most appropriate values for other parameters have been determined by a trial and error process. Table 2 denotes the results of the mentioned process.

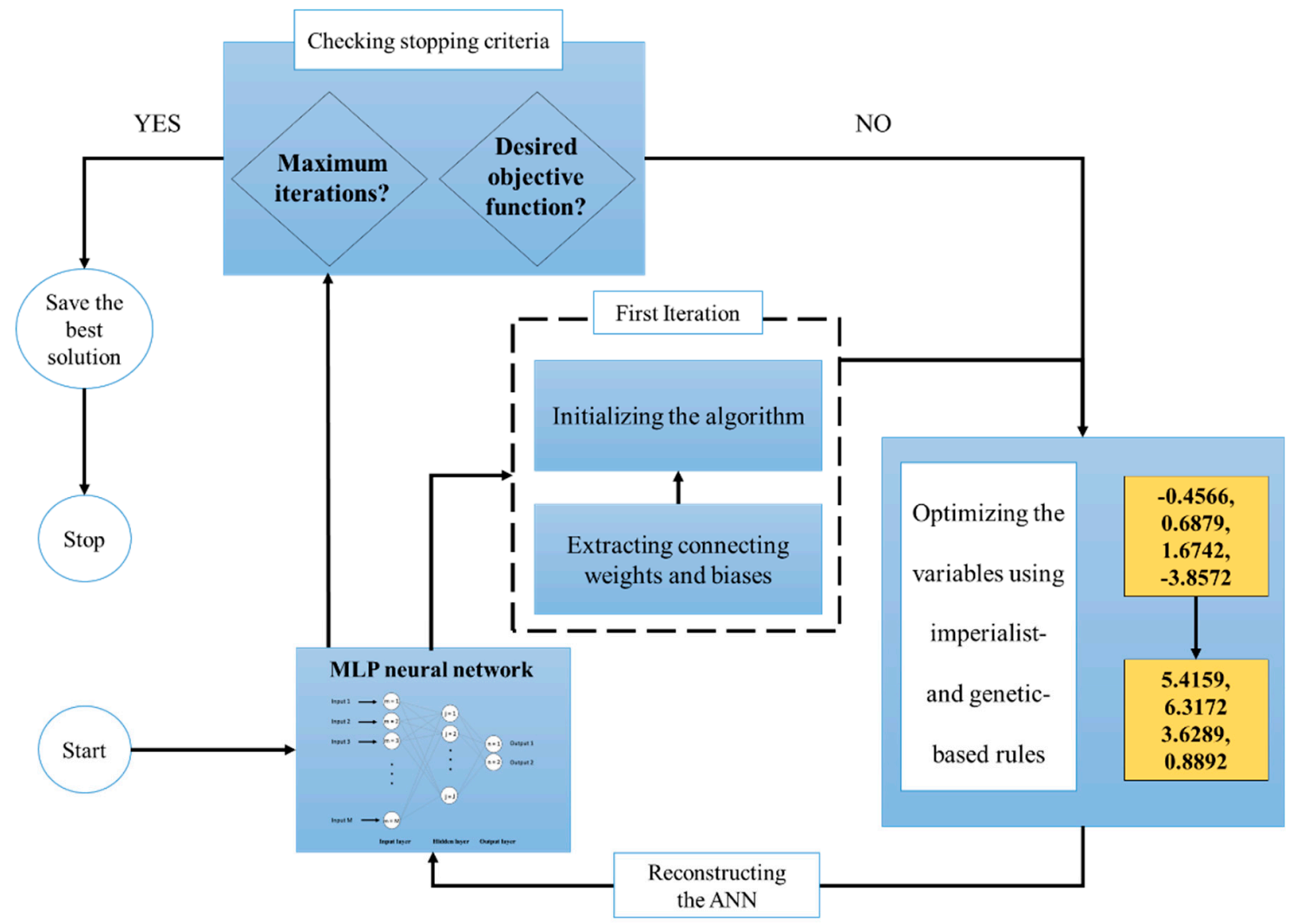

Figure 8. The incorporation of MLP with the proposed imperialist competition algorithm (ICA) and genetic algorithm (GA) algorithms.

Table 2. The optimal parameters of GA and ICA algorithms.

\begin{tabular}{|c|c|}
\hline $\begin{array}{c}\text { ICA-ANFIS } \\
\text { (Num. of Countries }=200, \text { and Num. of } \\
\text { Decades }=1000)\end{array}$ & $\begin{array}{c}\text { GA-ANN } \\
\text { (Population Size }=200 \text {, and Num. of } \\
\text { Generation }=1000)\end{array}$ \\
\hline $\begin{array}{l}\text { Revolution rate }=0.3 \\
\text { Num. of initial imperialists }=5 \\
\text { Damp ratio }=0.99\end{array}$ & $\begin{array}{l}\text { Crossover rate }=0.50 \\
\text { Mutation rate }=0.25\end{array}$ \\
\hline
\end{tabular}

Next, both parameters of "number of countries" and "population size" were considered to change between 50 to 500 with 50 intervals. The objective function was calculated for each iteration, and the results of this process are shown in Figures 9 and 10. Based on these figures, no significant change was observed after the 600th iteration for either GA and ICA algorithms. Accordingly, the lowest MSE obtained for the GA and ICA models with the number of countries and population size equal to 450 and 400 , respectively. 


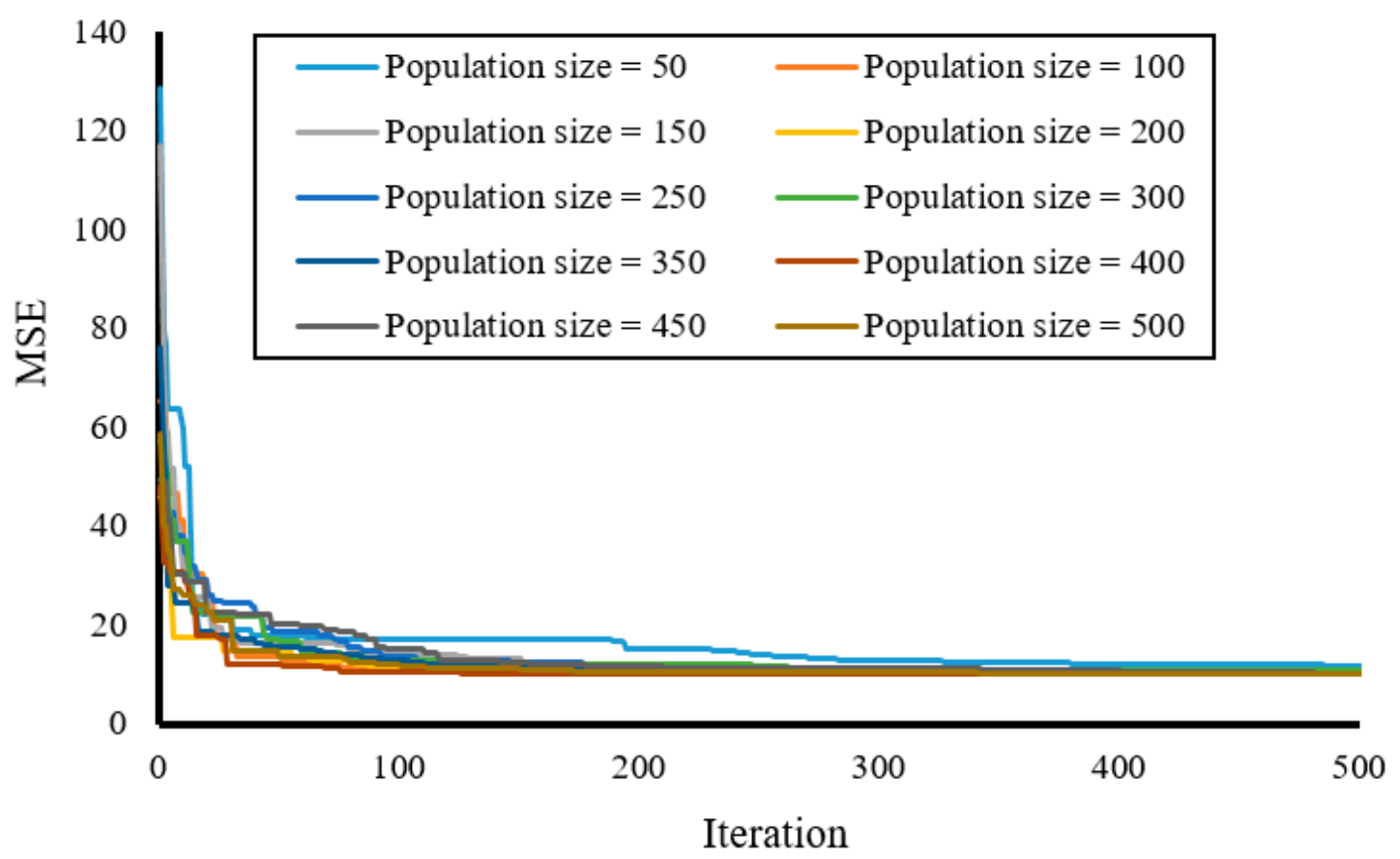

Figure 9. The sensitivity analysis for GA-ANN, based on the number of hidden neurons.

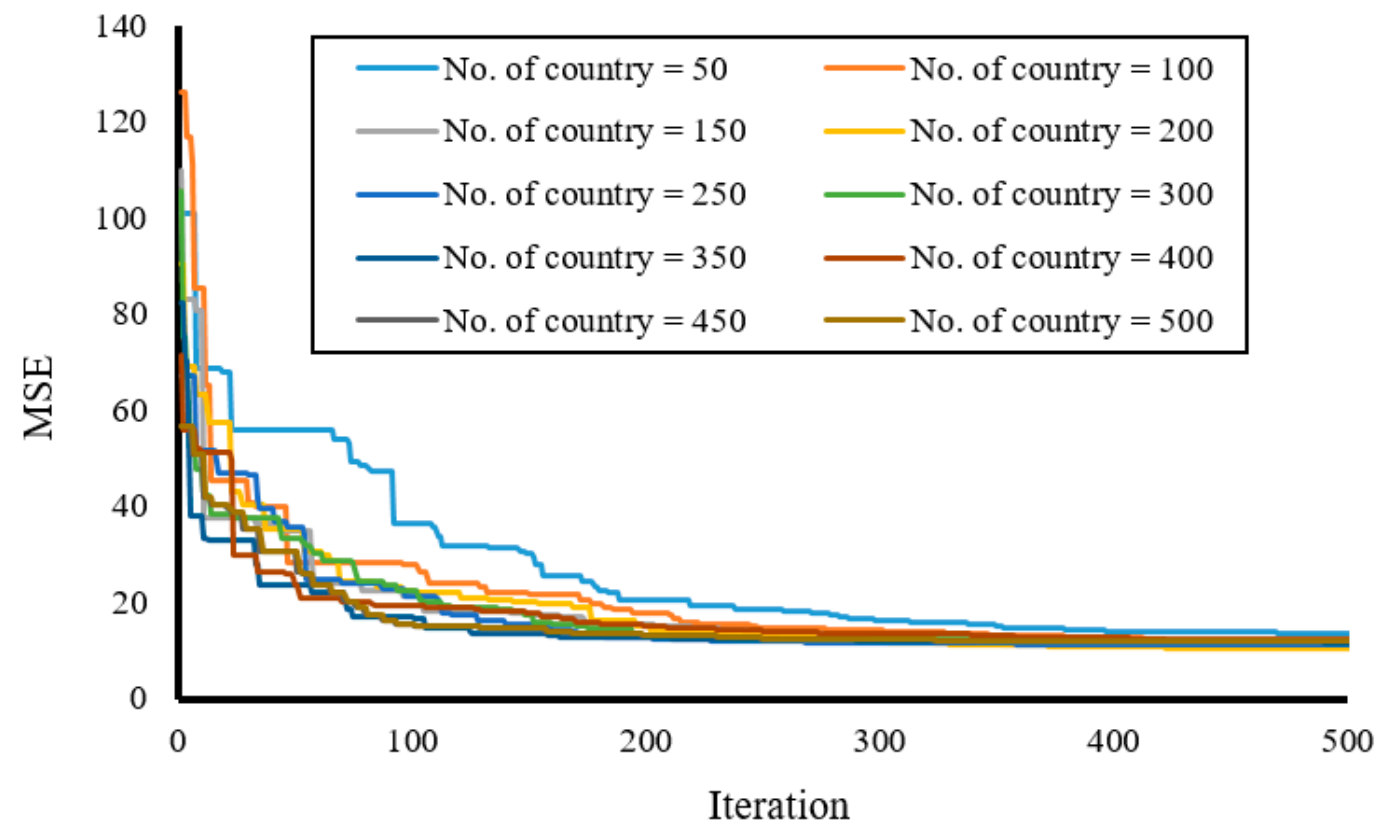

Figure 10. The sensitivity analysis for ICA-ANN, based on the number of countries.

\subsection{Model Assessment}

Using the programming software of MATLAB version 14.0 all three models were coded and implemented with their optimal architecture and the results are presented through various ways. A graphical comparison between the actual and predicted values of HL and CL is presented in Figures 11 and 12, as well as a chart showing the error of each sample (i.e., the difference between the actual and predicted values) and a histogram of the errors depicting the frequency of each error value. 

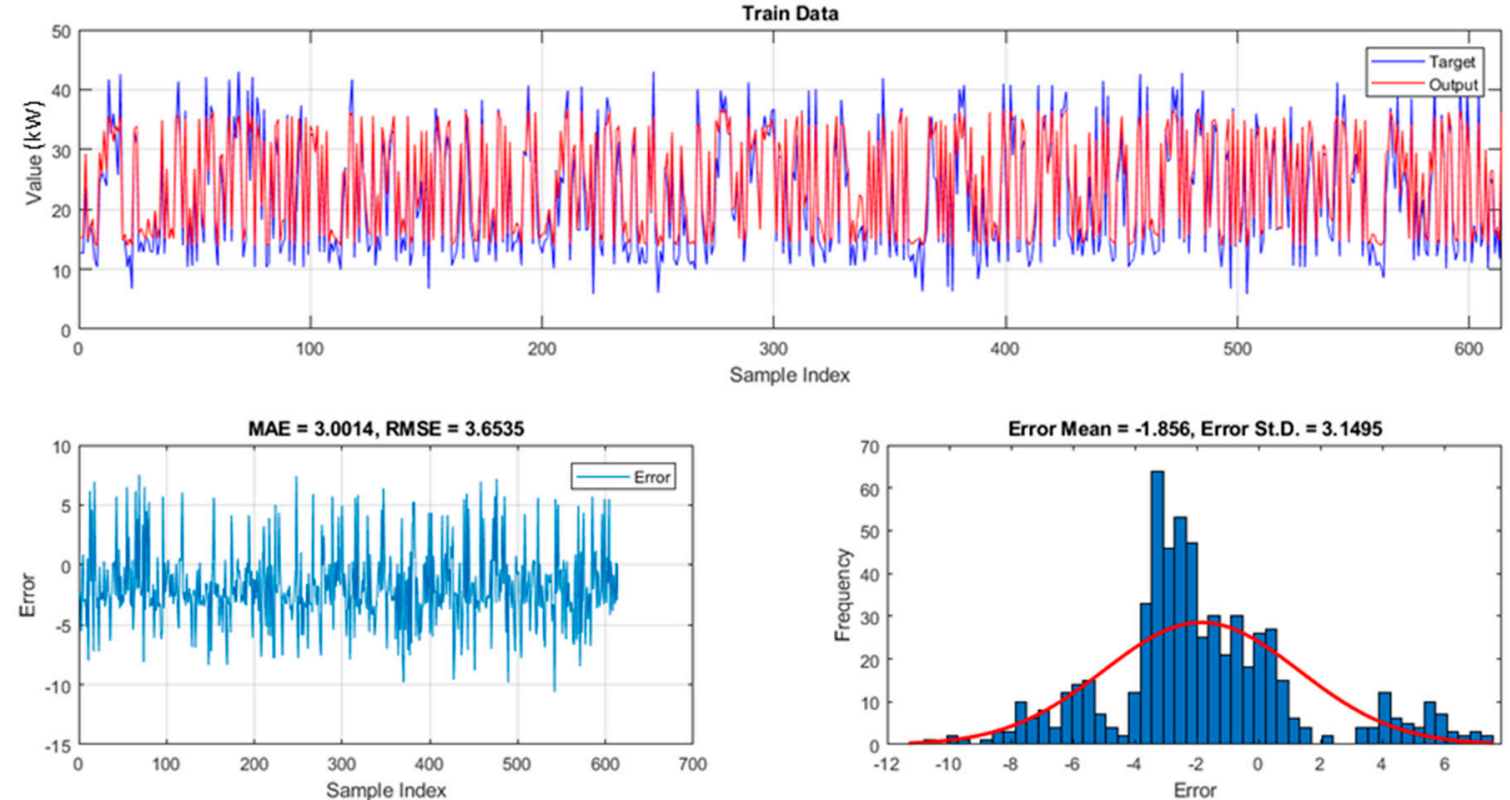

(a) ANN-Training HL
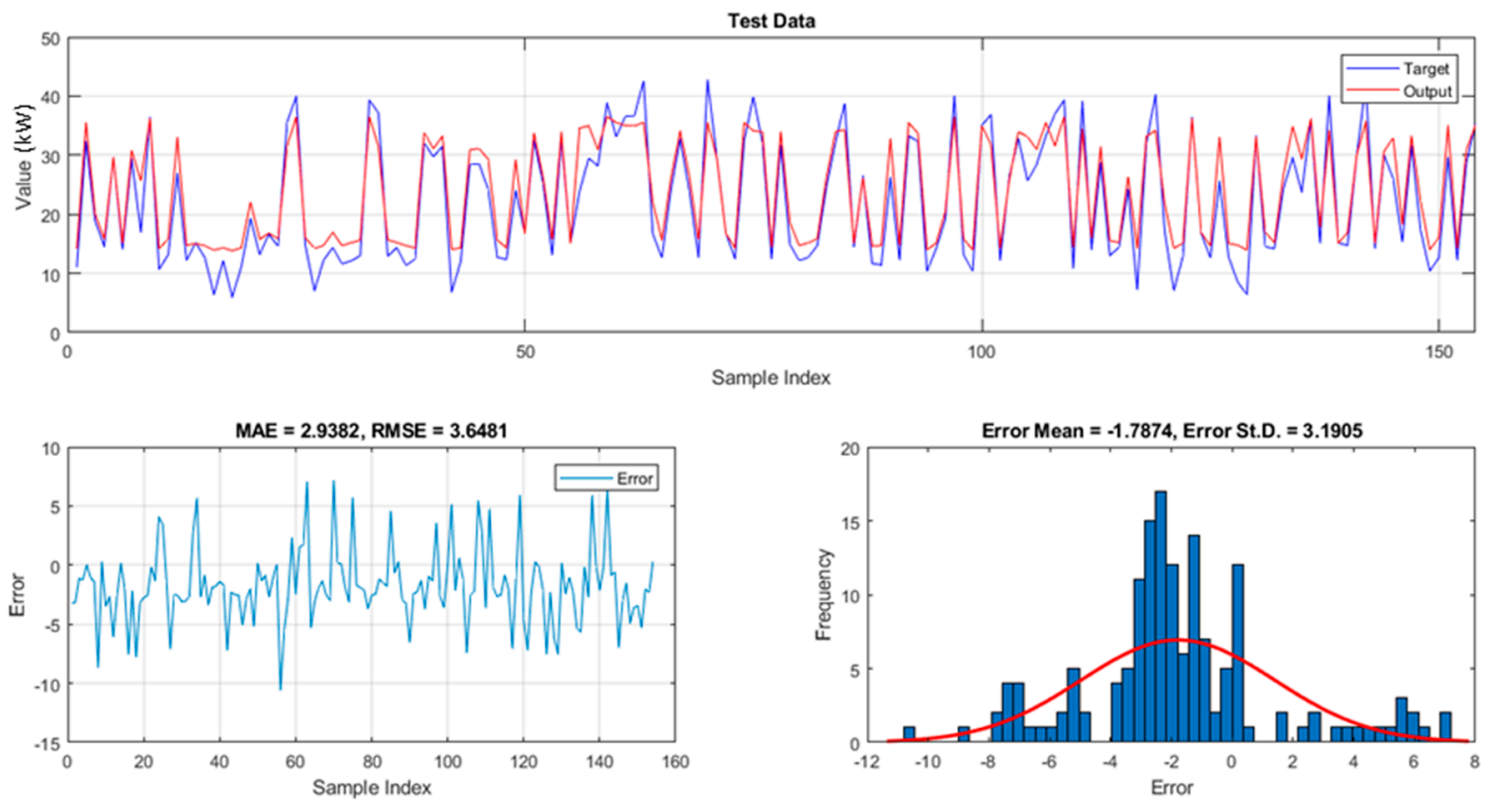

(b) ANN-Testing HL

Figure 11. Cont. 

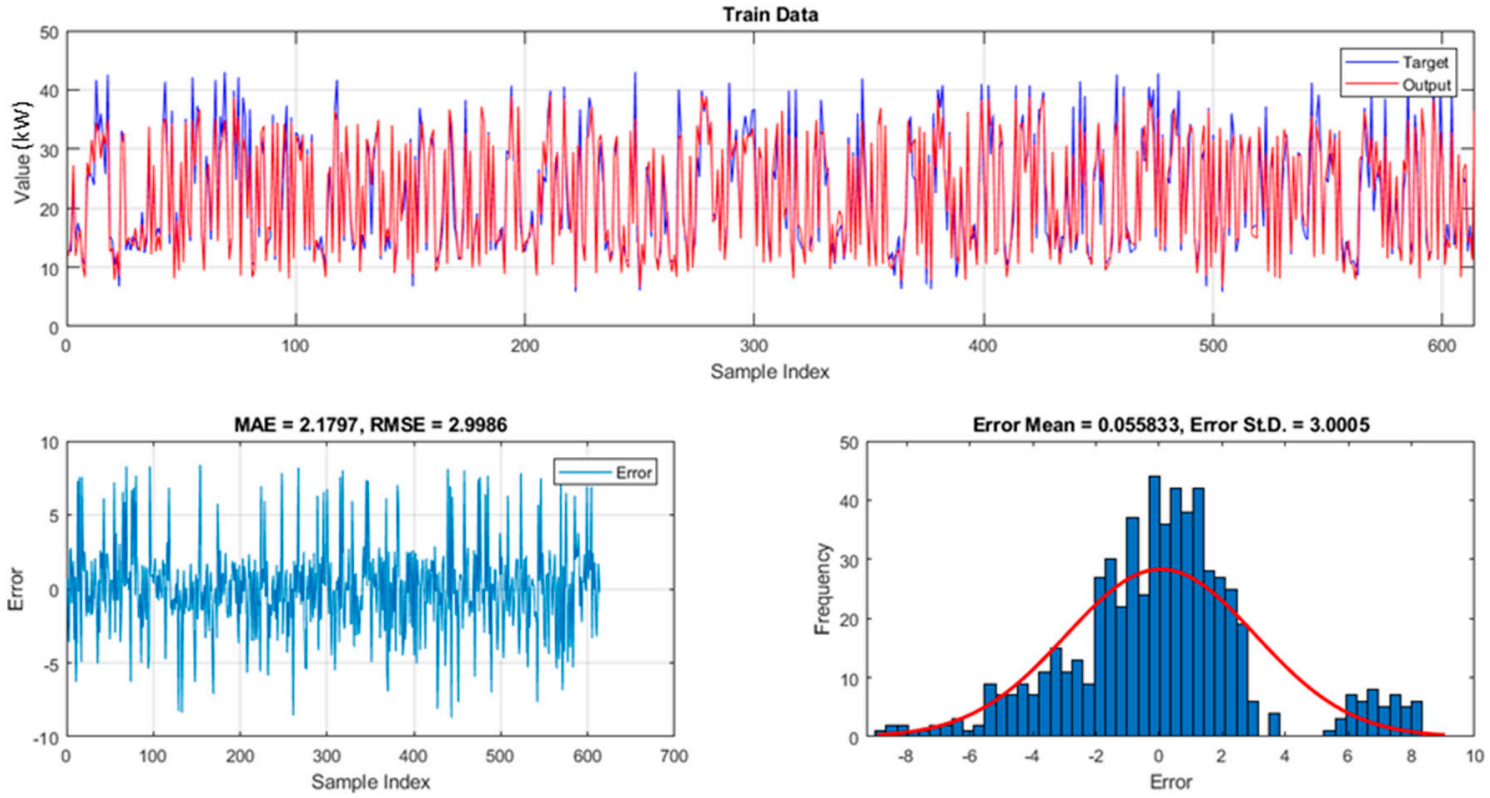

(c) GA-ANN-Training HL
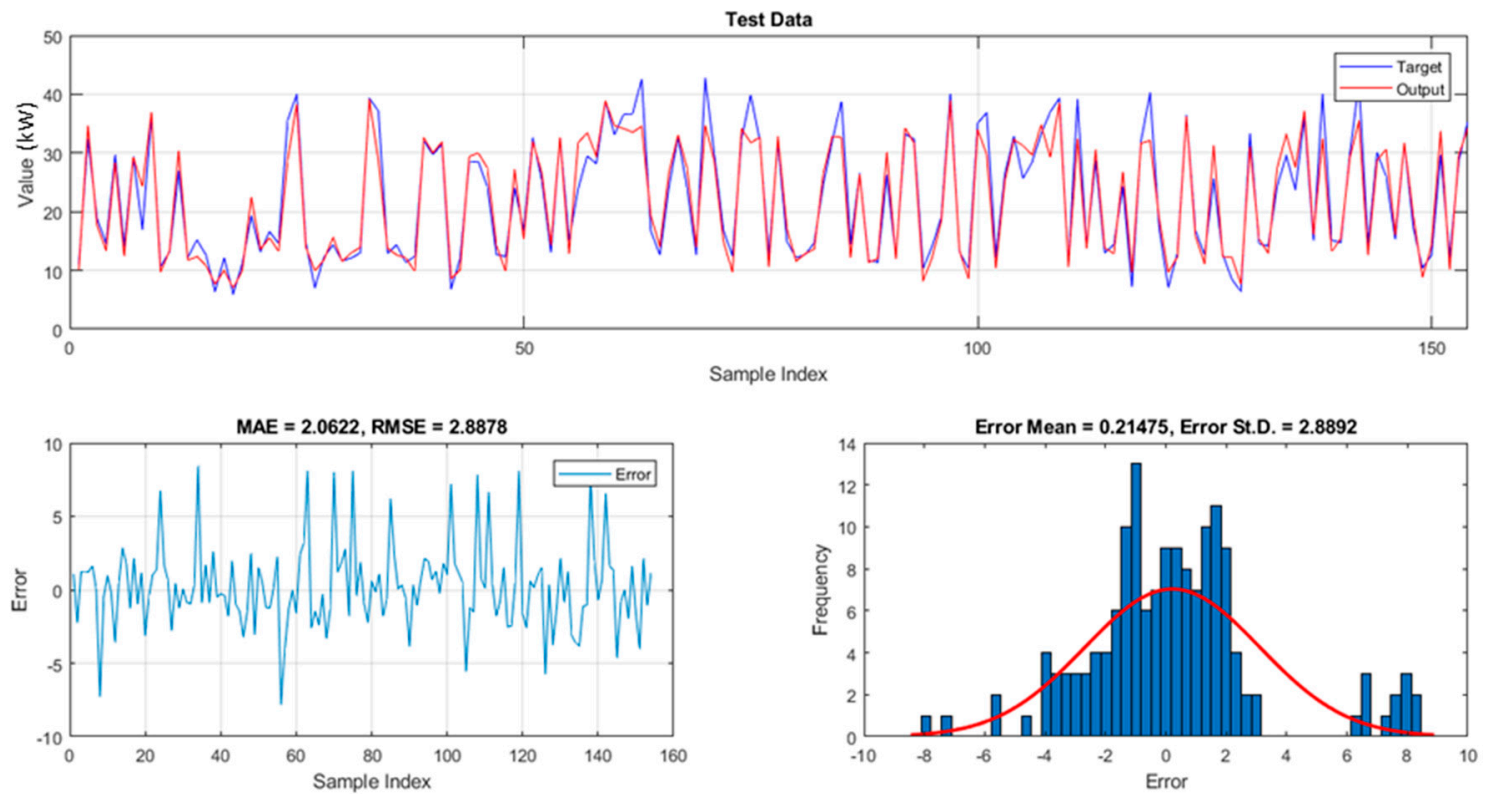

(d) GA-ANN-Testing HL

Figure 11. Cont. 

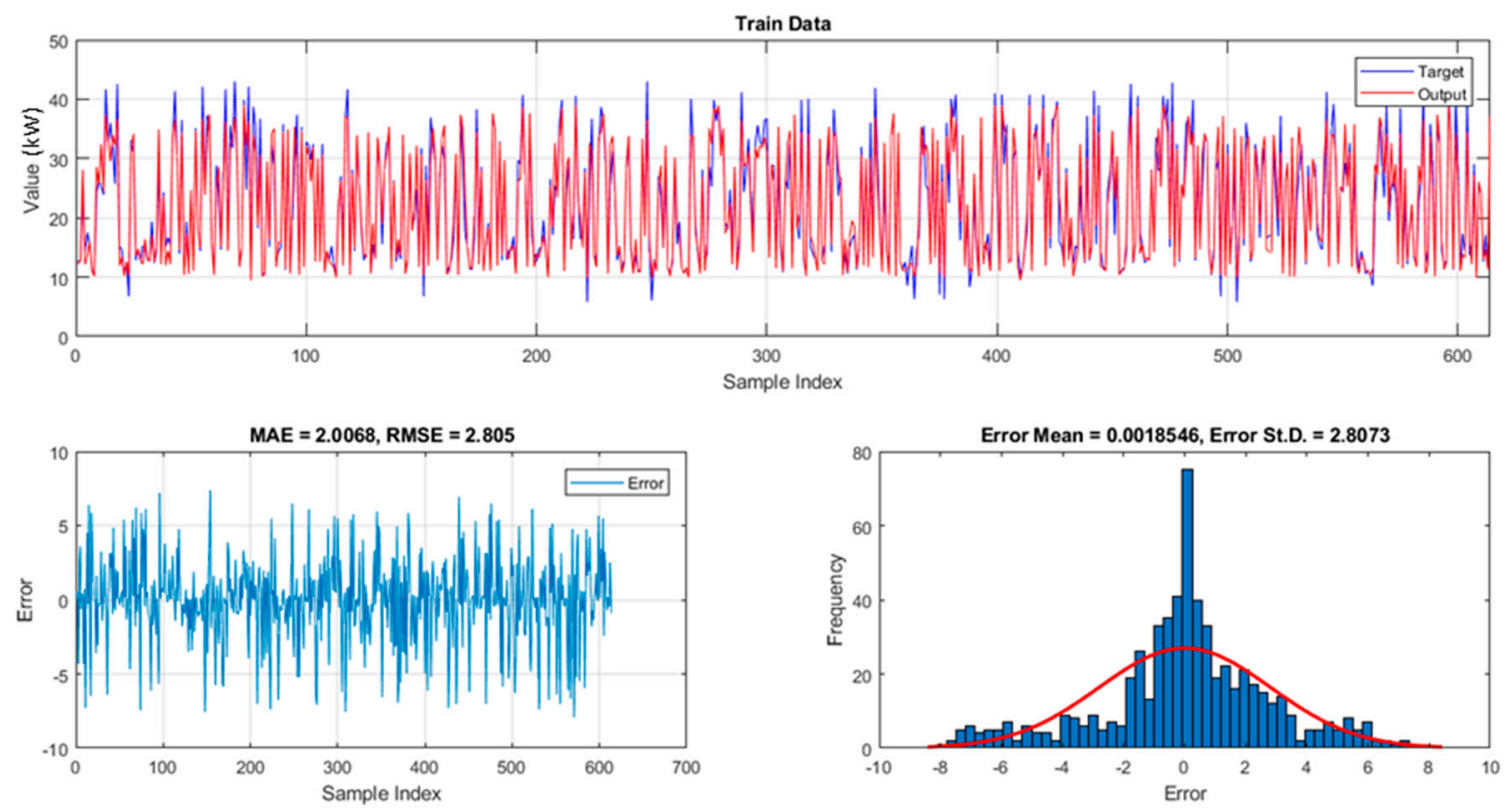

(e) ICA-ANN-Training HL
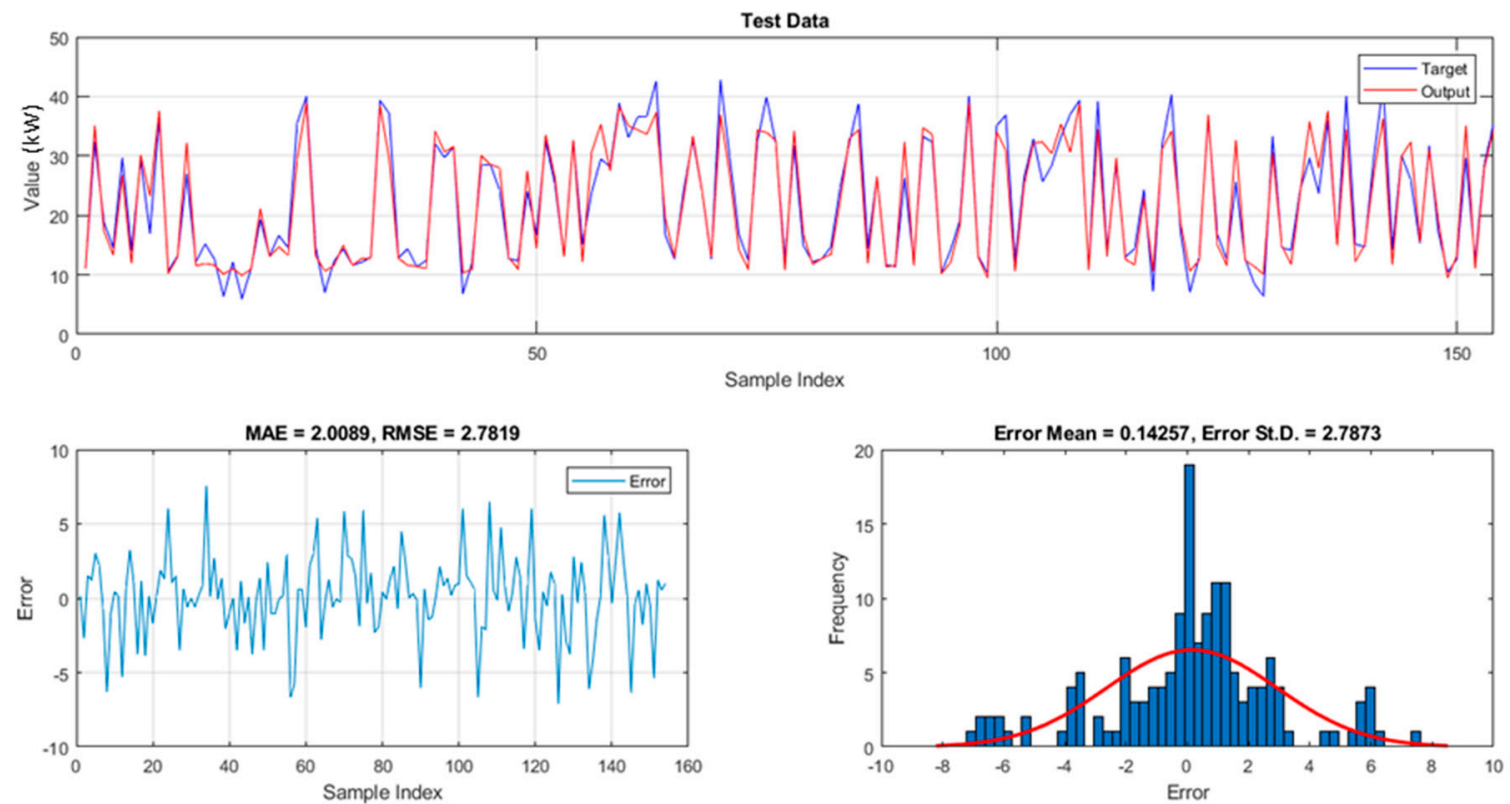

(f) ICA-ANN-Testing HL

Figure 11. A graphical view of the obtained results and the calculated errors for HL prediction. 

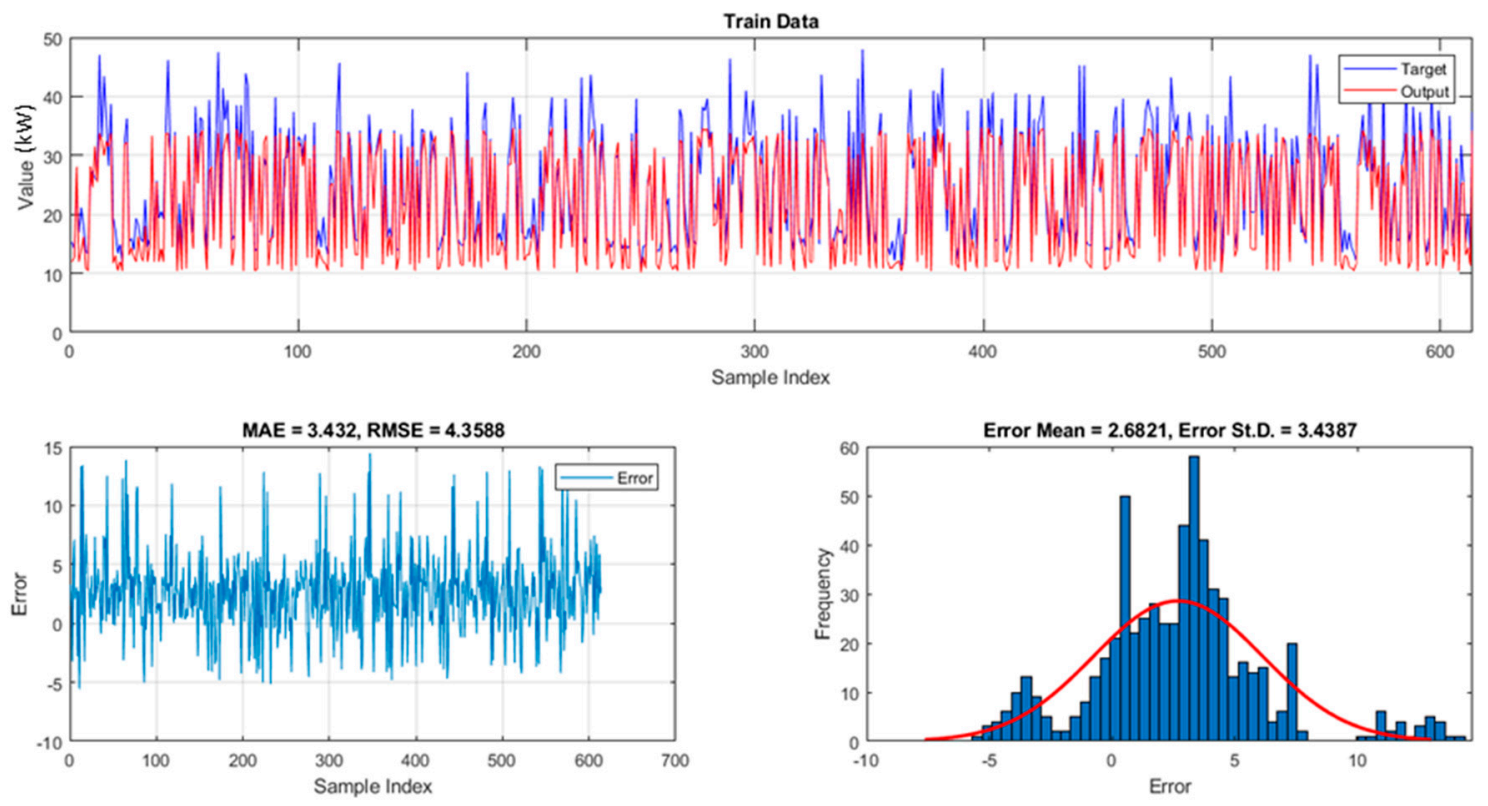

(a) ANN-Training CL
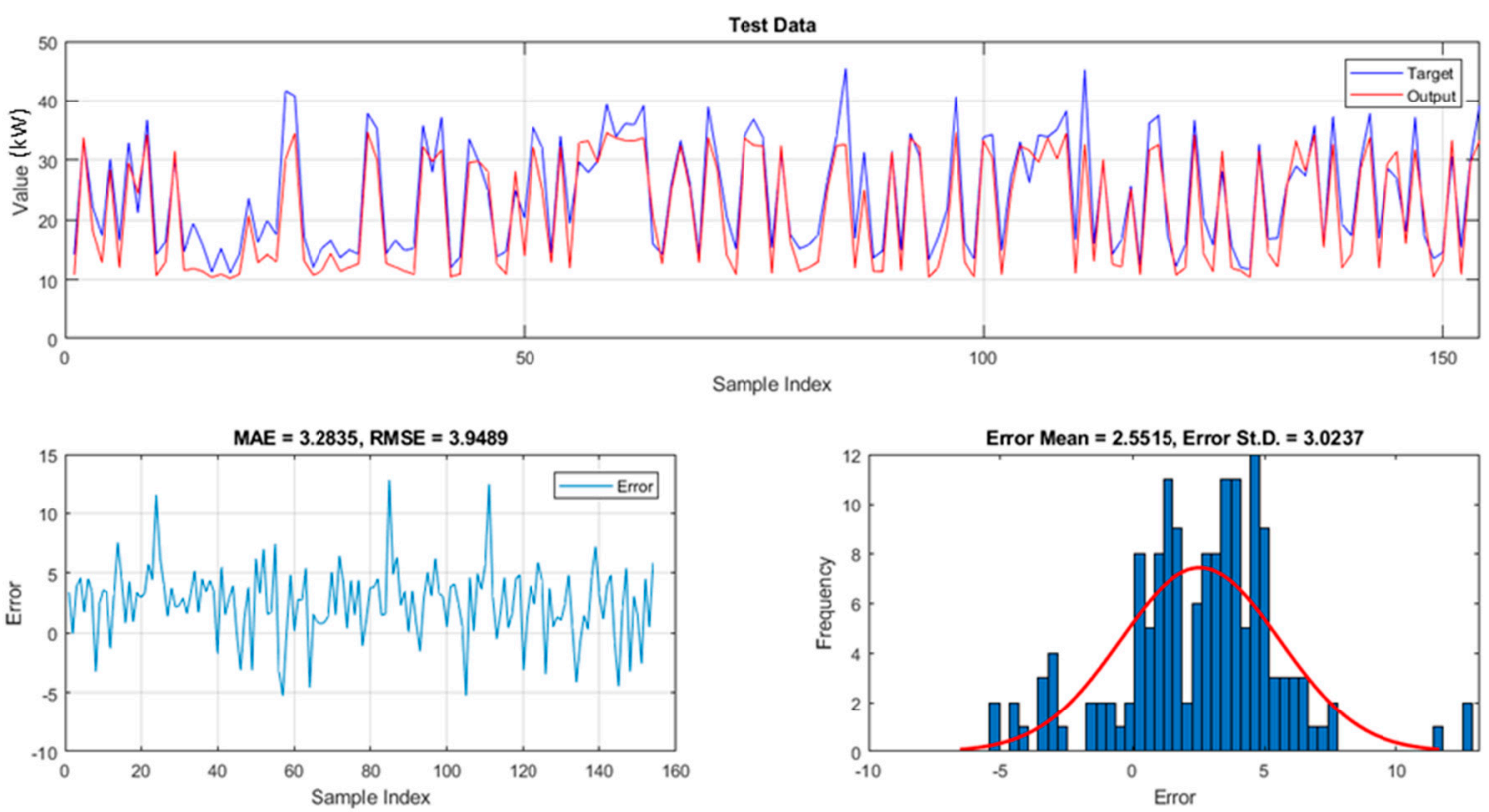

(b) ANN-Testing CL

Figure 12. Cont. 

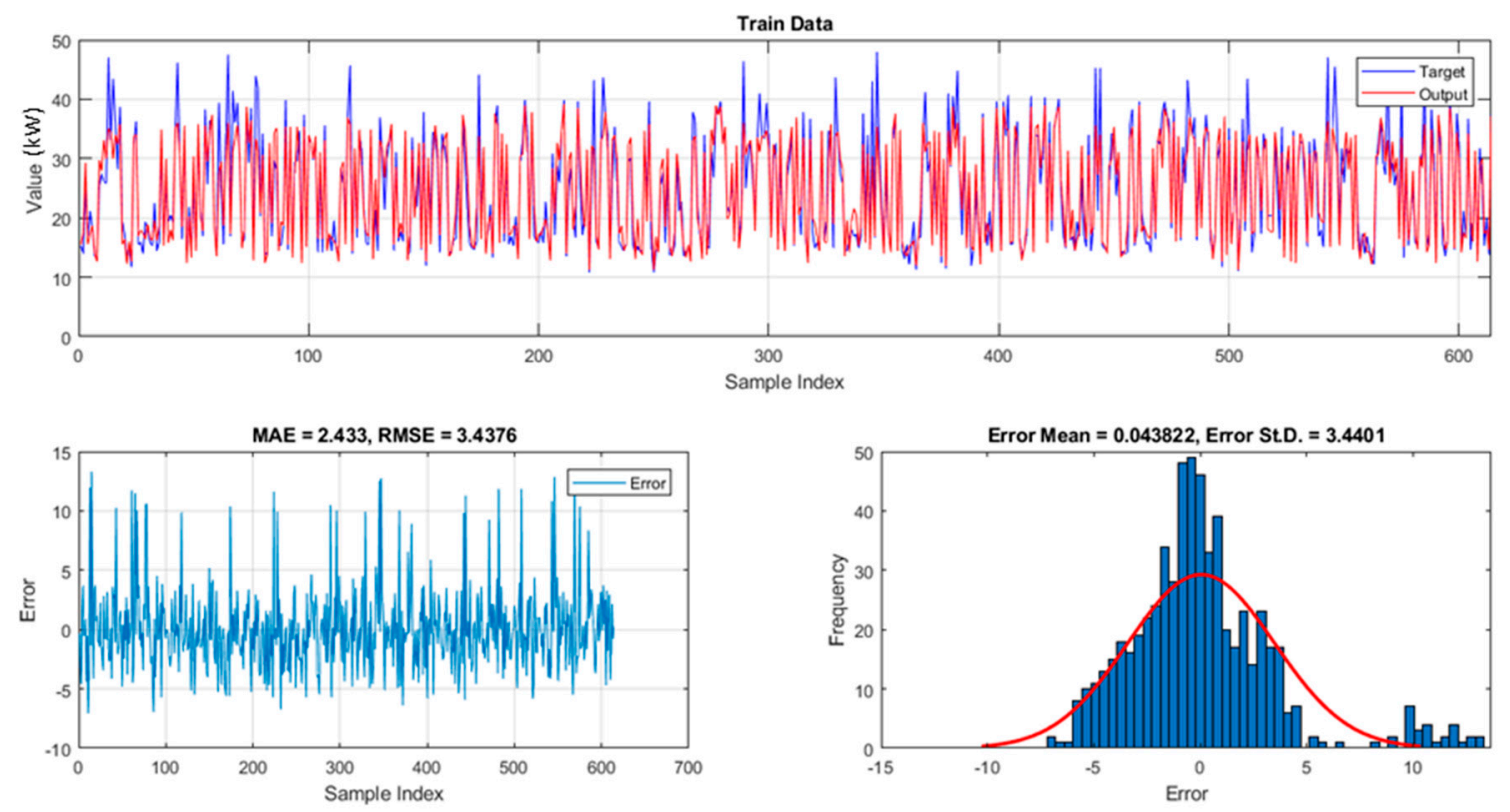

(c) GA-ANN-Training CL
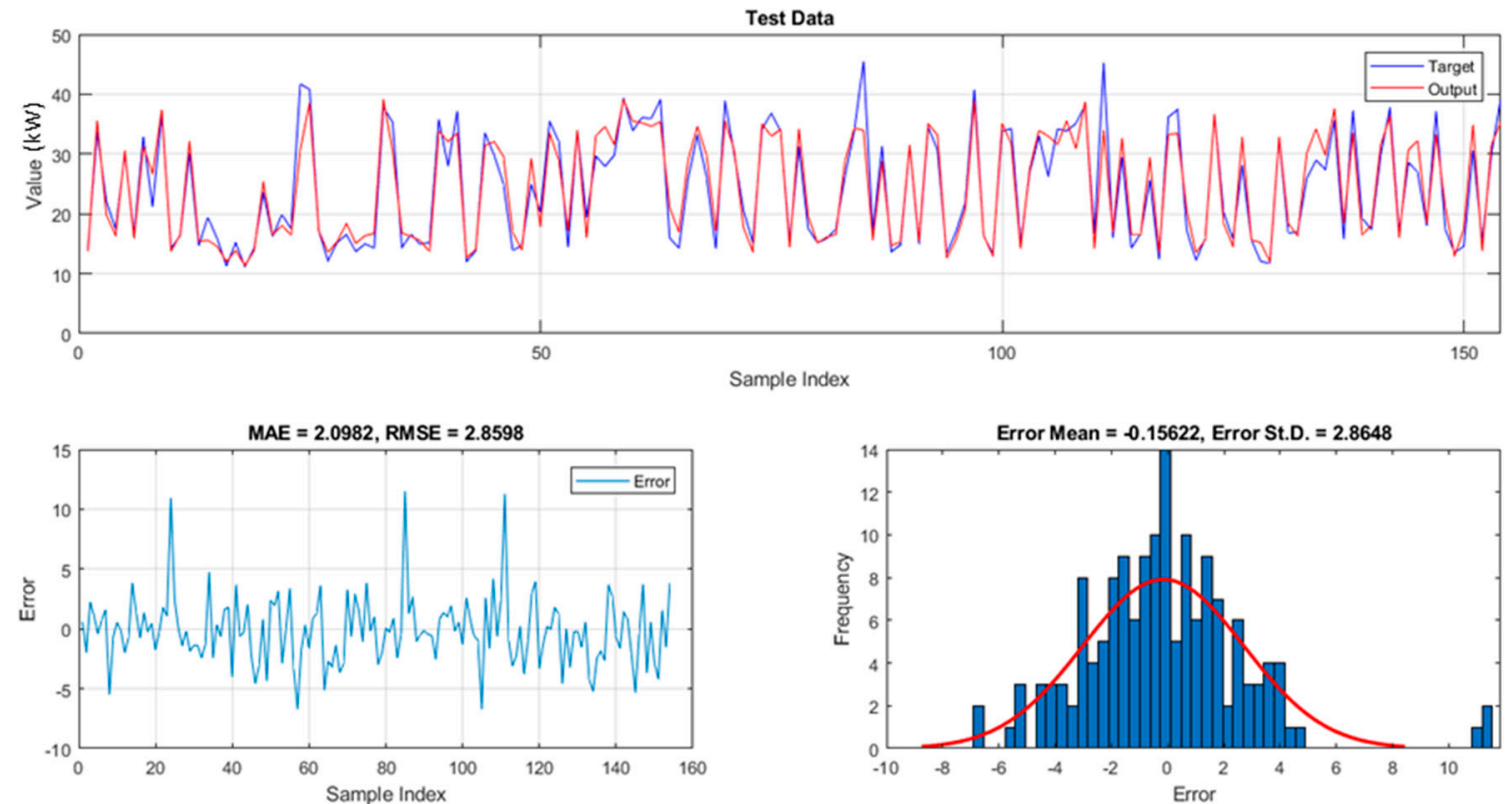

(d) GA-ANN-Testing CL

Figure 12. Cont. 

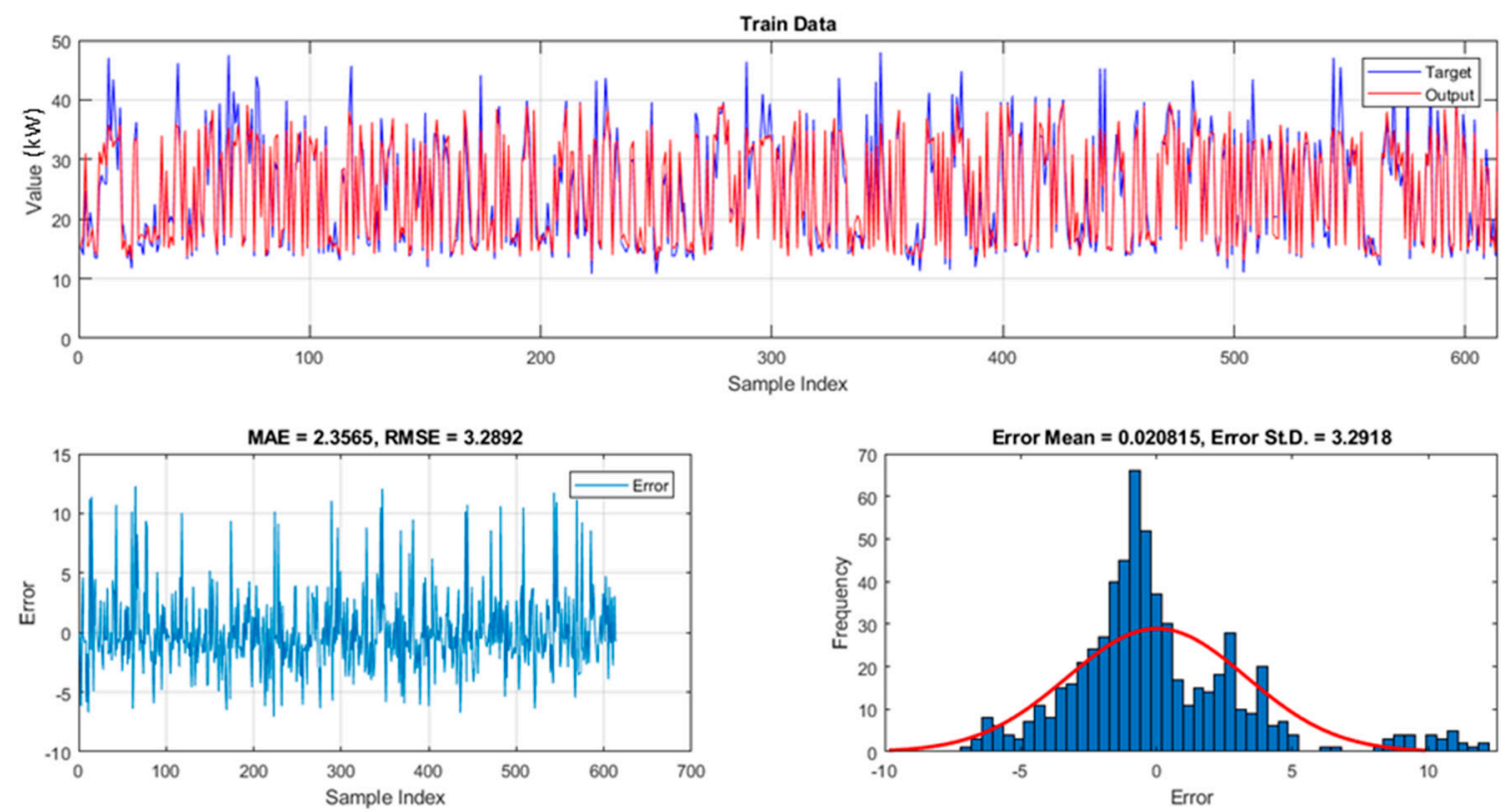

(e) ICA-ANN-Training CL
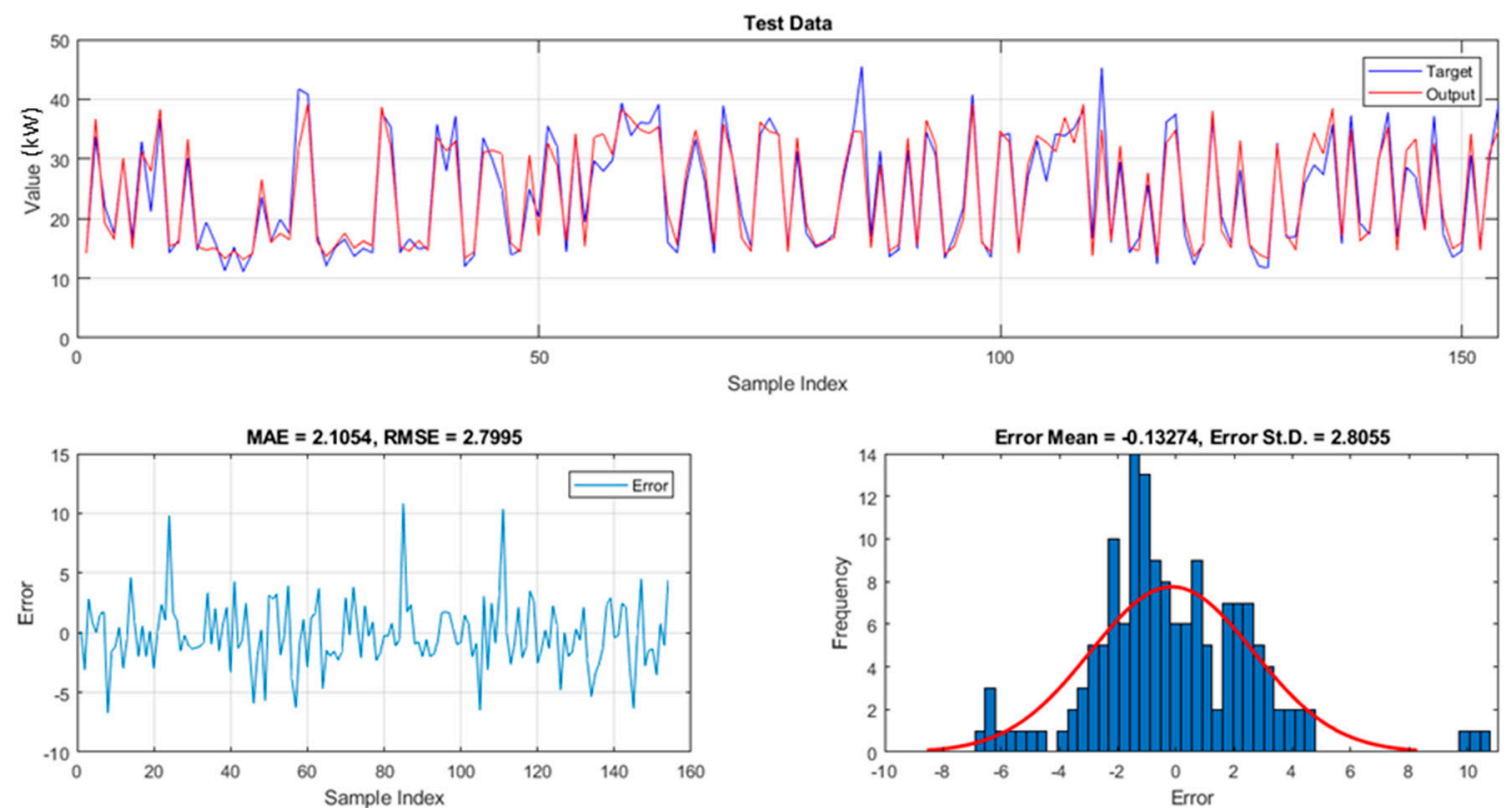

(f) ICA-ANN-Testing CL

Figure 12. A graphical view of the obtained results and the calculated errors for CL prediction.

Moreover, the accommodation between the targets and the outputs of ANN, GA-ANN, and ICA-ANN is depicted in the form of regression charts in Figures 13 and 14, respectively, for HL and CL modelling. The coefficient of determination $\left(R^{2}\right)$ is also calculated, which indicates the correlation between the mentioned parameters. This is noteworthy that $R^{2}$ is a statistical index which varies between 0 and 1 so that 1 represents an ideal prediction and vice versa. 


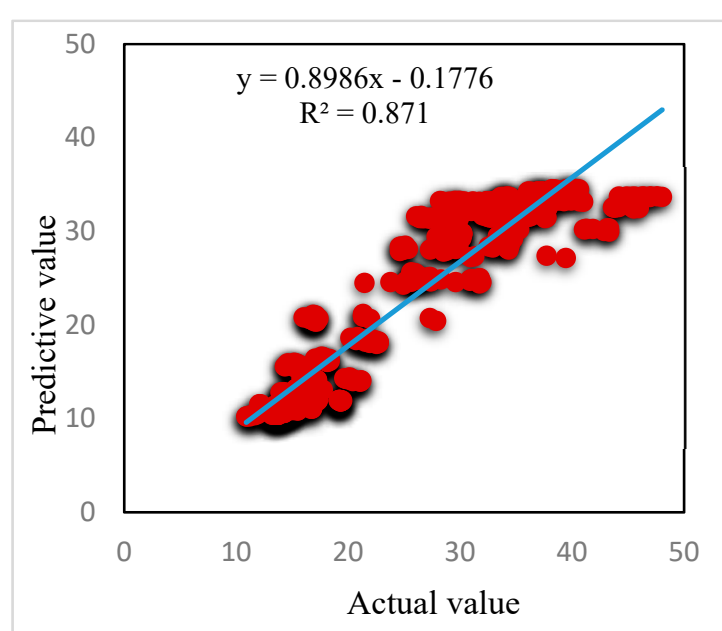

(a) ANN-Training HL

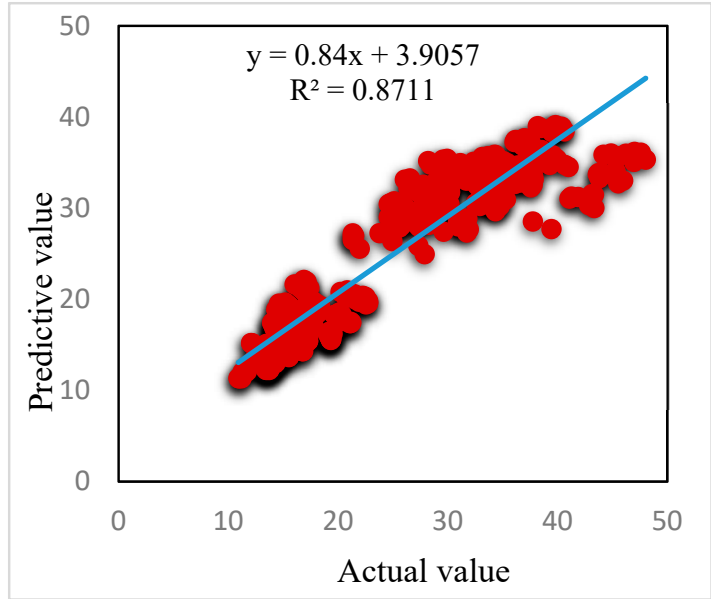

(c) GA-ANN-Training HL

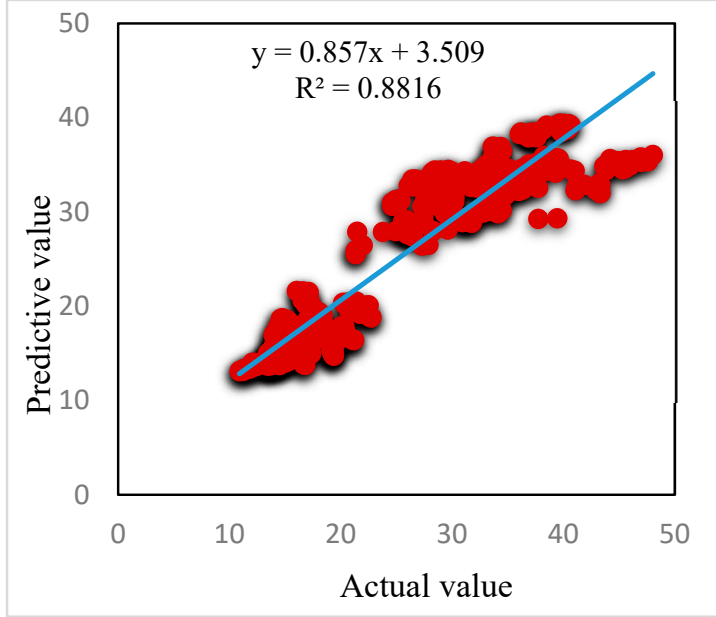

(e) ICA-ANN-Training HL

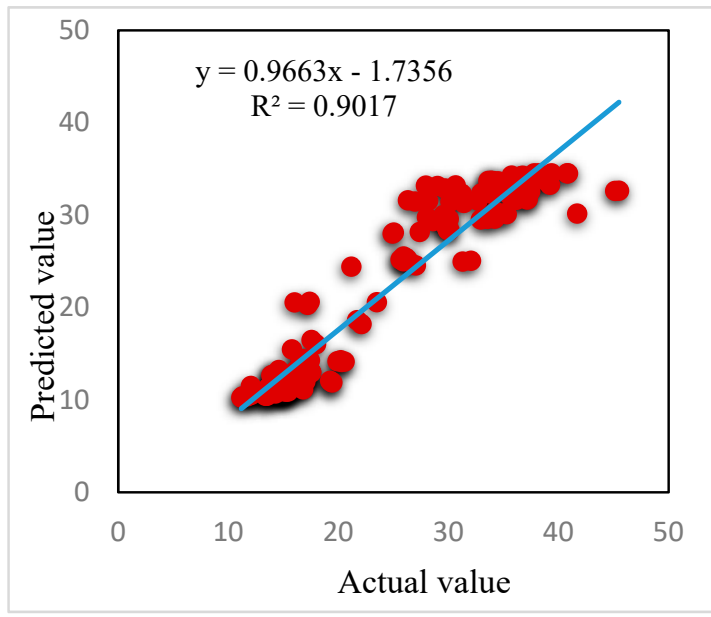

(b) ANN-Testing HL

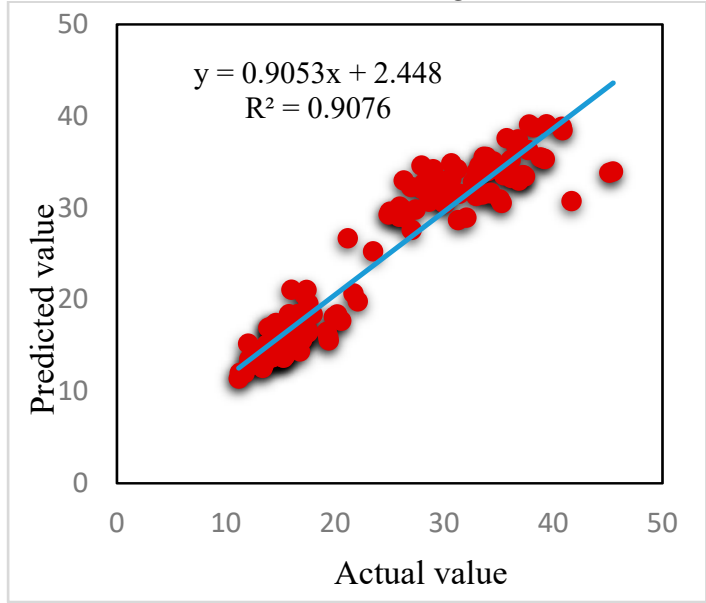

(d) GA-ANN-Testing HL

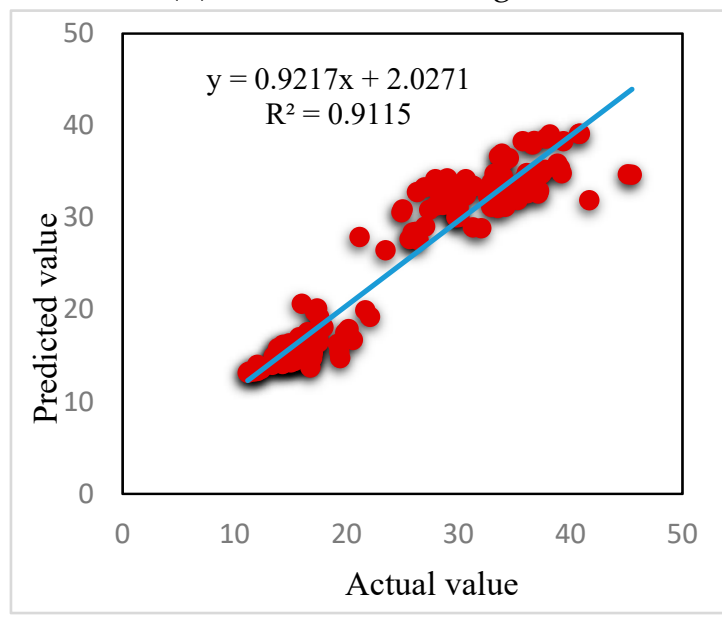

(f) ICA-ANN-Testing HL

Figure 13. The regression between the actual and predicted HL. 


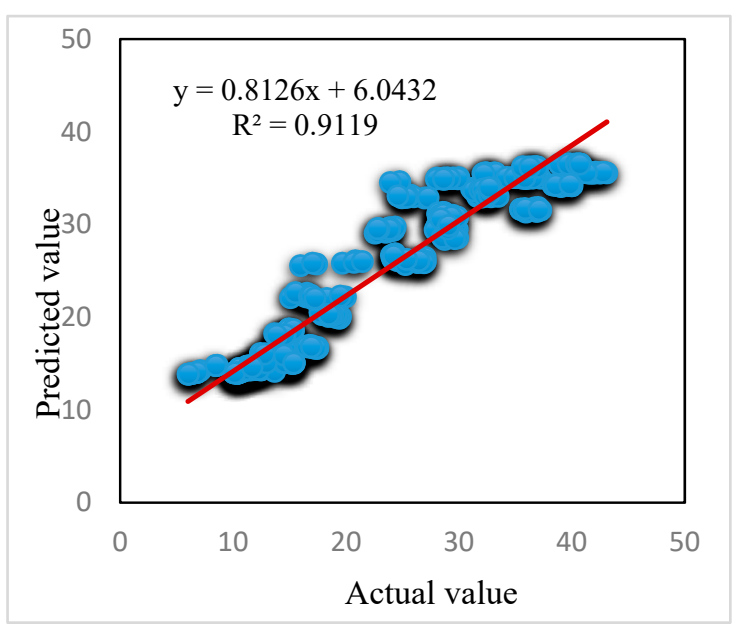

(a) ANN-Training CL.

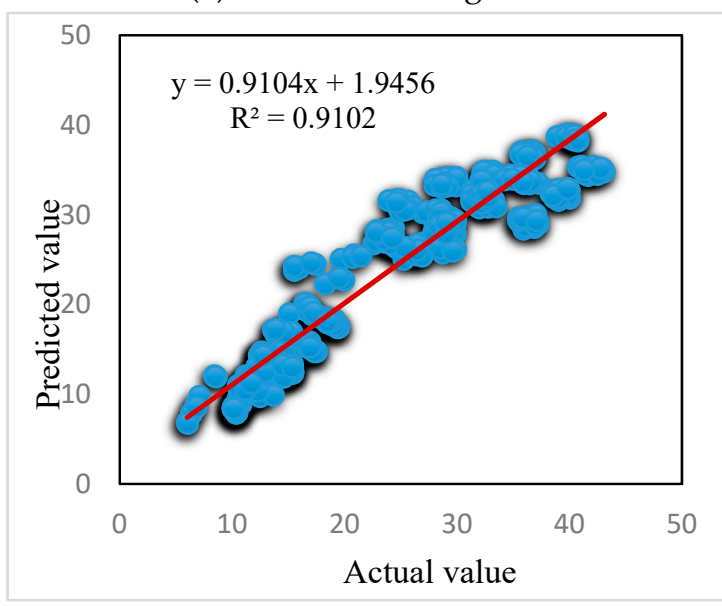

(c) GA-ANN-Training CL

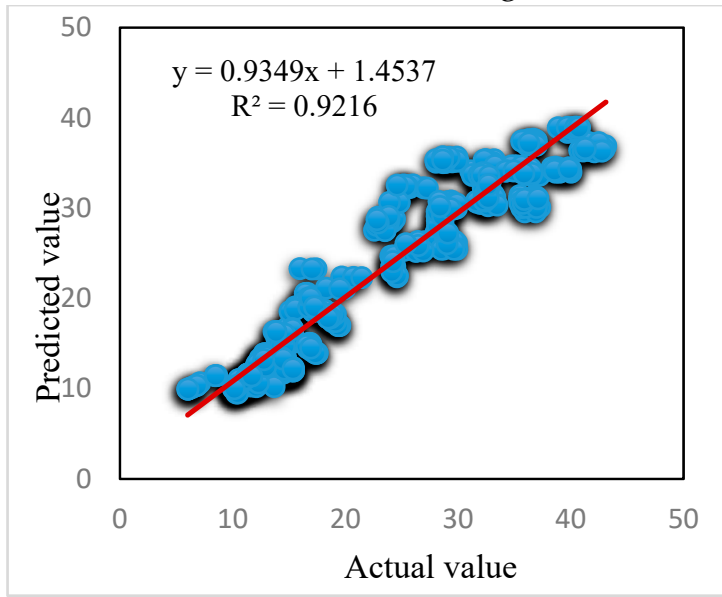

(e) ICA-ANN-Training CL

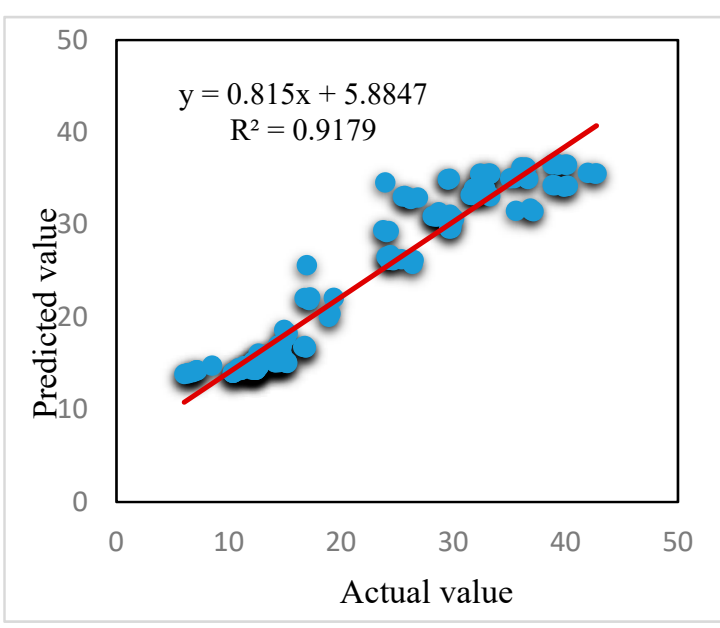

(b) ANN-Testing CL

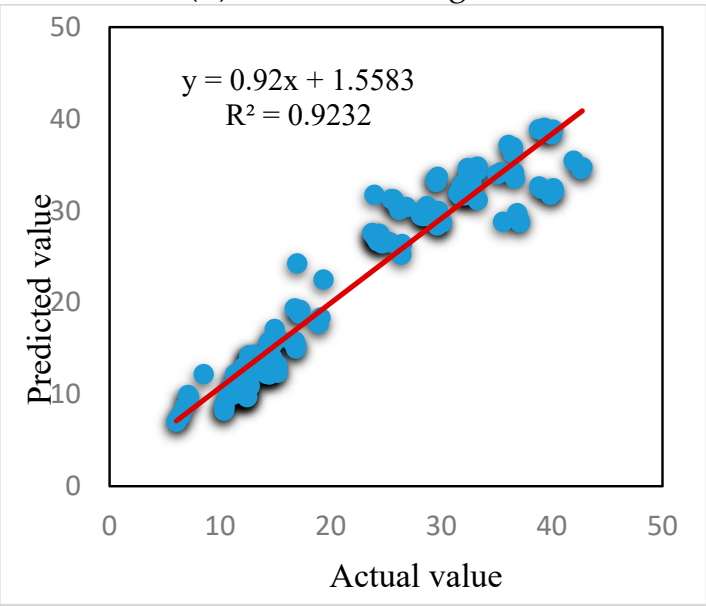

(d) GA-ANN-Testing CL

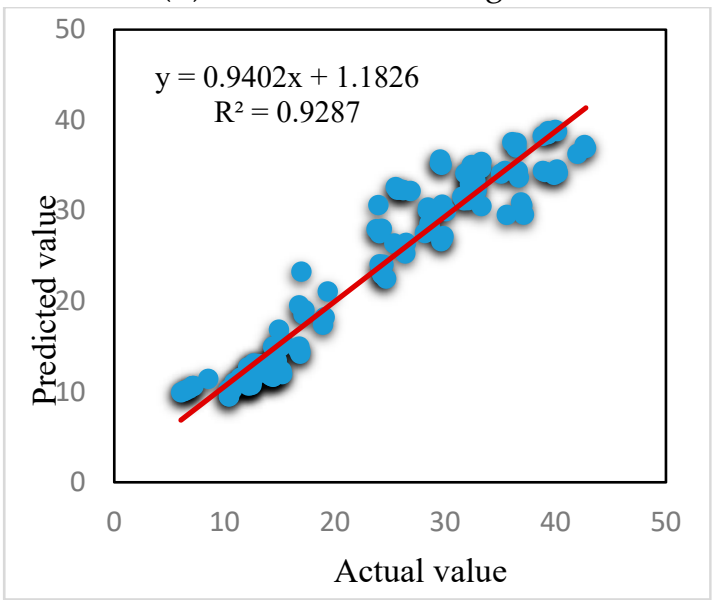

(f) ICA-ANN-Testing CL

Figure 14. The regression between the actual and predicted CL.

In the following, Table 3 summarizes the values of R2, RMSE, and MAE acquired for the training and testing phases of HL and CL prediction. It shall be noted that, to have a coherent presentation of the results, calculated values of $\mathrm{R}^{2}$, RMSE, and MAE are reported in the respective order for ANN, GA-ANN, and ICA-ANN in all explanations below. According to this table, by comparing the obtained $\mathrm{R}^{2}$ for the training HL $(0.8710,0.8711$, and 0.8816$)$ and testing $\operatorname{HL}(0.9017,0.9076$, and 0.9115$)$, it can be concluded that all three models have shown better performance for the testing dataset. In this 
regard, the outputs produced by ICA-ANN has the highest correlation with the actual HLs for both training and testing data. Also, the training $\operatorname{RMSE}(3.6535,2.9986$, and 2.8050) and MAE $(3.0014,2.1797$, and 2.0068) show that applying the GA and ICA evolutionary algorithms have a significant effect in decreasing the performance error. Similarly, the testing RMSE $(3.6481,2.8878$, and 2.7819) and MAE $(2.9382,2.0622$, and 2.0089) demonstrate that ICA-ANN has shown a higher accuracy compared to the GA-ANN and typical ANN in forecasting the HL of residential buildings. As for CL prediction, the calculated $\mathrm{R}^{2}$ for the training $(0.9119,0.9102$, and 0.9216$)$ and testing samples $(0.9179,0.9232$, and 0.9287) prove that ICA has performed slightly better than GA in improving the ANN performance. This is while ANN has achieved a higher value of $\mathrm{R}^{2}$ compared to GA-ANN model $(0.9119>0.9102)$. The computed RMSE for the training $(4.3588,3.4376$, and 3.2892) and testing phases $(3.9489,2.8598$, and 2.7995) revealed that combining ANN with GA and ICA has led to decreasing the root mean square error as 0.9212 and 1.0696 , and 1.0891 and 1.1494, respectively for the training and testing instances. Referring to Table 3, however, GA-ANN outperformed ICA-ANN in the case of testing MAE $(3.2835,2.0982$, and 2.1054), but the results of the training MAE $(3.4320,2.4330$, and 2.3565) support the previous claims (i.e., the superiority of ICA-ANN method).

Table 3. Obtained MAE, RMSE, and $\mathrm{R}^{2}$ for ANN, GA-ANN, and ICA-ANN results.

\begin{tabular}{|c|c|c|c|c|c|c|c|c|c|c|c|c|}
\hline \multirow{4}{*}{ Models } & \multicolumn{12}{|c|}{ Data } \\
\hline & \multicolumn{6}{|c|}{ Training } & \multicolumn{6}{|c|}{ Testing } \\
\hline & \multicolumn{3}{|c|}{ HL } & \multicolumn{3}{|c|}{ CL } & \multicolumn{3}{|c|}{ HL } & \multicolumn{3}{|c|}{ CL } \\
\hline & $\mathbf{R}^{2}$ & RMSE & MAE & $\mathbf{R}^{2}$ & RMSE & MAE & $\mathbf{R}^{2}$ & RMSE & MAE & $\mathbf{R}^{2}$ & RMSE & MAE \\
\hline ANN & 0.8710 & 3.6535 & 3.0014 & 0.9119 & 4.3588 & 3.4320 & 0.9017 & 3.6481 & 2.9382 & 0.9179 & 3.9489 & 3.2835 \\
\hline GA-ANN & 0.8711 & 2.9986 & 2.1797 & 0.9102 & 3.4376 & 2.4330 & 0.9076 & 2.8878 & 2.0622 & 0.9232 & 2.8598 & 2.0982 \\
\hline ICA-ANN & 0.8816 & 2.8050 & 2.0068 & 0.9216 & 3.2892 & 2.3565 & 0.9115 & 2.7819 & 2.0089 & 0.9287 & 2.7995 & 2.1054 \\
\hline
\end{tabular}

\section{Conclusions and Remarks}

Recent years have witnessed the development of new models to give an accurate approximation from the energy consumption of the buildings. In this paper, we employed two metaheuristic algorithms to overcome the drawbacks of the backpropagation algorithms for this aim. In this sense, a typical multilayer-perceptron neural network (ANN) was synthesized with genetic algorithm (GA-ANN) and imperialist competition algorithm (ICA-ANN) to estimate the heating load (HL) and cooling load (CL) of a building with residential use. To this end, eight influential energy parameters, including relative compactness, surface area, wall area, roof area, overall height, orientation, glazing area, glazing area distribution were considered as the inputs of the designed networks. Considering twelve different buildings, four glazing areas, five distribution scenarios, and four orientations, 768 buildings were modelled and analyzed in Ecotect environment. Among those, 80\% (614 records) were devoted to training the ANN, GA-ANN, and ICA-ANN models, and the efficiency of them was evaluated by the remaining 20\% (154 records). The proposed models were implemented in their optimal conditions and three famous statistical indices of the coefficient of determination $\left(R^{2}\right)$, mean absolute error (MAE), root mean square error (RMSE) was used to evaluate the accuracy of each method. We achieved the following results in this study:

- Artificial intelligence techniques can act as an efficient approach for analyzing the heating and cooling load of the buildings.

- Optimizing the computational parameters (i.e., the weights and biases) of the ANN using the GA and ICA has a significant effect on its performance in terms of both pattern learning and prediction.

- $\quad$ The computed $\mathrm{R}^{2}$ for both training (HL: 0.8710, 0.8711, and 0.8816-CL: 0.9119, 0.9102, and 0.9216) and testing (HL: 0.9017, 0.9076, and 0.9115—CL: 0.9179, 0.9232, and 0.9287) showed that ICA helps the ANN to increase the correlation of the results an also outperforms GA. 
- Based on the calculated RMSE, the training error of ANN decreased as $17.92 \%$ and $23.22 \%$ for the $\mathrm{HL}$, and $21.13 \%$ and $24.53 \%$ for CL, respectively by applying GA and ICA. These values were $20.84 \%$ and $23.74 \%$ for $\mathrm{HL}$ and $27.57 \%$ and $29.10 \%$ for CL about the validation error.

- As for MAE, the training error of ANN decreased as $27.38 \%$ and $33.14 \%$ for the HL, and $29.11 \%$ and $31.34 \%$ for CL, respectively by applying GA and ICA. These values were $29.81 \%$ and $31.63 \%$ for $\mathrm{HL}$ and $36.10 \%$ and $35.88 \%$ for $\mathrm{CL}$ about the validation error.

- From the comparison viewpoint, ICA outperformed GA in performance improvement of multi-layer perceptron neural network in the case of this study.

Author Contributions: D.T.B. and H.M. performed experiments and field data collection; H.M. wrote the manuscript, discussion and analyzed the data. D.A., L.K.F., edited, restructured, and professionally optimized the manuscript.

Funding: This research received no external funding.

Acknowledgments: This work was financially supported by Ton Duc Thang University.

Conflicts of Interest: The authors declare no conflict of interest.

$\begin{array}{ll}\text { Abbreviations } \\ \text { CL } & \text { Cooling load } \\ \text { HL } & \text { Heating load } \\ \text { HVAC } & \text { Heating ventilation and air conditioning } \\ \text { EPB } & \text { Energy performance of buildings } \\ \text { PER } & \text { Primary energy requirement } \\ \text { DeST } & \text { Designer's simulation toolkit } \\ \text { AI } & \text { Artificial intelligence } \\ \text { ANN } & \text { Artificial neural network } \\ \text { PLS } & \text { Partial least squares regression } \\ \text { ANFIS } & \text { Adaptive neuro-fuzzy inference system } \\ \text { RF } & \text { Random forest } \\ \text { SVM } & \text { Support vector machine } \\ \text { BPNN } & \text { Back propagation neural network } \\ \text { GRNN } & \text { General regression neural network } \\ \text { RBFNN } & \text { Radial basis function neural network } \\ \text { RMSE } & \text { Root mean square error } \\ \text { MAE } & \text { Mean relative error } \\ \text { R } & \text { Coefficient of determination } \\ \text { CV } & \text { Coefficients of variance } \\ \text { MLP } & \text { Multi-layer perceptron } \\ \text { AHP } & \text { Analytic hierarchy process } \\ & \end{array}$

\section{References}

1. International Energy Agency (IEA). Key World Energy Statistics; International Energy Agency: Paris, France, 2015.

2. McQuiston, F.C.; Parker, J.D. Heating, Ventilating, and Air Conditioning: Analysis and Design; John Wiley \& Sons Inc.: New York, NY, USA, 1982.

3. Castaldo, V.L.; Pigliautile, I.; Rosso, F.; Cotana, F.; De Giorgio, F.; Pisello, A.L. How subjective and non-physical parameters affect occupants' environmental comfort perception. Energy Build. 2018, 178, 107-129. [CrossRef]

4. Sant'Anna, D.; Dos Santos, P.H.; Vianna, N.S.; Romero, M.A. Indoor environmental quality perception and users' satisfaction of conventional and green buildings in Brazil. Sustain. Cities Soc. 2018, 43, 95-110. [CrossRef]

5. Caniato, M.; Bettarello, F.; Ferluga, A.; Marsich, L.; Schmid, C.; Fausti, P. Thermal and acoustic performance expectations on timber buildings. Build. Acoust. 2017, 24, 219-237. [CrossRef] 
6. European Parliament and Council. Directive 2010/31/EU of the European Parlia-ment and of the Council of 19 May 2010 on the energy performance of buildings(recast). Off. J. Eur. Union 2010, L153, 13-35.

7. Kwok, A.G.; Rajkovich, N.B. Addressing climate change in comfort standards. Build. Environ. 2010, 45, 18-22. [CrossRef]

8. Yao, R.; Li, B.; Steemers, K. Energy policy and standard for built environment in China. Renew. Energy 2005, 30, 1973-1988. [CrossRef]

9. Fanti, M.P.; Mangini, A.M.; Roccotelli, M. A simulation and control model for building energy management. Control Eng. Pract. 2018, 72, 192-205. [CrossRef]

10. Egan, J.; Finn, D.; Soares, P.H.; Baumann, V.A.; Aghamolaei, R.; Beagon, P.; Neu, O.; Pallonetto, F.; O'Donnell, J. Definition of a useful minimal-set of accurately-specified input data for Building Energy Performance Simulation. Energy Build. 2018, 165, 172-183. [CrossRef]

11. Zhao, H.X.; Magoulès, F. A review on the prediction of building energy consumption. Renew. Sustain. Energy Rev. 2012, 16, 3586-3592. [CrossRef]

12. Park, J.; Lee, S.J.; Kim, K.H.; Kwon, K.W.; Jeong, J.W. Estimating thermal performance and energy saving potential of residential buildings using utility bills. Energy Build. 2016, 110, 23-30. [CrossRef]

13. Yezioro, A.; Dong, B.; Leite, F. An applied artificial intelligence approach towards assessing building performance simulation tools. Energy Build. 2008, 40, 612-620. [CrossRef]

14. Yan, D.; Xia, J.; Tang, W.; Song, F.; Zhang, X.; Jiang, Y. DeST—An integrated building simulation toolkit Part I: Fundamentals. In Building Simulation; Springer: Berlin, Germany, 2008.

15. Crawley, D.B.; Lawrie, L.K.; Winkelmann, F.C.; Buhl, W.F.; Huang, Y.J.; Pedersen, C.O.; Strand, R.K.; Liesen, R.J.; Fisher, D.E.; Witte, M.J.; et al. EnergyPlus: Creating a new-generation building energy simulation program. Energy Build. 2001, 33, 319-331. [CrossRef]

16. York, D.; Cappiello, C.; Olson, K. DOE-2 Reference Manual: Version 2.1 C; Los Alamos National Laboratory Solar Energy Group: Los Alamos, NM, USA, 1984.

17. O'Neill, Z.; O'Neill, C. Development of a probabilistic graphical model for predicting building energy performance. Appl. Energy 2016, 164, 650-658. [CrossRef]

18. Catalina, T.; Virgone, J.; Blanco, E. Development and validation of regression models to predict monthly heating demand for residential buildings. Energy Build. 2008, 40, 1825-1832. [CrossRef]

19. Yu, Z.; Haghighat, F.; Fung, B.C.; Yoshino, H. A decision tree method for building energy demand modeling. Energy Build. 2010, 42, 1637-1646. [CrossRef]

20. Moayedi, H.; Mehrabi, M.; Mosallanezhad, M.; Rashid, A.S.; Pradhan, B. Modification of landslide susceptibility mapping using optimized PSO-ANN technique. Eng. Comput. 2019, 35, 967-984. [CrossRef]

21. Seyedashraf, O.; Mehrabi, M.; Akhtari, A.A. Novel approach for dam break flow modeling using computational intelligence. J. Hydrol. 2018, 559, 1028-1038. [CrossRef]

22. Escandón, R.; Ascione, F.; Bianco, N.; Mauro, G.M.; Suárez, R.; Sendra, J.J. Thermal comfort prediction in a building category: Artificial Neural Network generation from calibrated models for a social housing stock in southern Europe. Appl. Therm. Eng. 2019, 150, 492-505. [CrossRef]

23. Fan, C.; Wang, J.; Gang, W.; Li, S. Assessment of deep recurrent neural network-based strategies for short-term building energy predictions. Appl. Energy 2019, 236, 700-710. [CrossRef]

24. Pino-Mejías, R.; Pérez-Fargallo, A.; Rubio-Bellido, C.; Pulido-Arcas, J.A. Comparison of linear regression and artificial neural networks models to predict heating and cooling energy demand, energy consumption and CO2 emissions. Energy 2017, 118, 24-36. [CrossRef]

25. Deb, C.; Eang, L.S.; Yang, J. Forecasting diurnal cooling energy load for institutional buildings using Artificial Neural Networks. Energy Build. 2016, 121, 284-297. [CrossRef]

26. Li, Q.; Meng, Q.; Cai, J.; Yoshino, H.; Mochida, A. Predicting hourly cooling load in the building: A comparison of support vector machine and different artificial neural networks. Energy Convers. Manag. 2009, 50, 90-96. [CrossRef]

27. Yun, K.; Luck, R.; Mago, P.J.; Cho, H. Building hourly thermal load prediction using an indexed ARX model. Energy Build. 2012, 54, 225-233. [CrossRef]

28. Yao, Y.; Lian, Z.; Liu, S.; Hou, Z. Hourly cooling load prediction by a combined forecasting model based on analytic hierarchy process. Int. J. Therm. Sci. 2004, 43, 1107-1118. [CrossRef]

29. Dong, B.; Cao, C.; Lee, S.E. Applying support vector machines to predict building energy consumption in tropical region. Energy Build. 2005, 37, 545-553. [CrossRef] 
30. Zhao, J.; Liu, X. A hybrid method of dynamic cooling and heating load forecasting for office buildings based on artificial intelligence and regression analysis. Energy Build. 2018, 174, 293-308. [CrossRef]

31. Li, K.; Su, H.; Chu, J. Forecasting building energy consumption using neural networks and hybrid neuro-fuzzy system: A comparative study. Energy Build. 2011, 43, 2893-2899. [CrossRef]

32. Tsanas, A.; Xifara, A. Accurate quantitative estimation of energy performance of residential buildings using statistical machine learning tools. Energy Build. 2012, 49, 560-567. [CrossRef]

33. Catalina, T.; Iordache, V.; Caracaleanu, B. Multiple regression model for fast prediction of the heating energy demand. Energy Build. 2013, 57, 302-312. [CrossRef]

34. McCulloch, W.S.; Pitts, W. A logical calculus of the ideas immanent in nervous activity. Bull. Math. Biophys. 1943, 5, 115-133. [CrossRef]

35. Moayedi, H.; Rezaei, A. An artificial neural network approach for under-reamed piles subjected to uplift forces in dry sand. Neural Comput.Appl. 2019, 31, 327-336. [CrossRef]

36. Moayedi, H.; Hayati, S. Applicability of a CPT-Based Neural Network Solution in Predicting Load-Settlement Responses of Bored Pile. Int. J. Geomech. 2018, 18, 06018009. [CrossRef]

37. Holland, J.H. Genetic algorithms. Sci. Am. 1992, 267, 66-73. [CrossRef]

38. Whitley, D. A genetic algorithm tutorial. Stat. Comput. 1994, 4, 65-85. [CrossRef]

39. Moayedi, H.; Mehdi, R.; Abolhasan, S.; Wan, A.W.J.; Safuan, A.R.A. Optimization of ANFIS with GA and PSO estimating $\alpha$ in driven shafts. Eng. Comput. 2019, 35, 1-12.

40. Atashpaz-Gargari, E.; Lucas, C. Imperialist competitive algorithm: An algorithm for optimization inspired by imperialistic competition. In 2007 IEEE Congress on Evolutionary Computation; IEEE: Piscataway, NJ, USA, 2007.

41. Al Dossary, M.A.; Nasrabadi, H. Well placement optimization using imperialist competitive algorithm. J. Pet. Sci. Eng. 2016, 147, 237-248. [CrossRef]

42. Moayedi, H.; Armaghani, D.J. Optimizing an ANN model with ICA for estimating bearing capacity of driven pile in cohesionless soil. Eng. Comput. 2018, 34, 347-356. [CrossRef]

43. Roberts, A.; Marsh, A. ECOTECT: Environmental Prediction in Architectural Education; Cardiff University: Wales, UK, 2001.

44. Mosallanezhad, M.; Moayedi, H. Developing hybrid artificial neural network model for predicting uplift resistance of screw piles. Arab. J. Geosci. 2017, 10, 479. [CrossRef]

45. Armaghani, D.J.; Mohamad, E.T.; Momeni, E.; Monjezi, M.; Narayanasamy, M.S. Prediction of the strength and elasticity modulus of granite through an expert artificial neural network. Arab. J. Geosci. 2016, 9, 48. [CrossRef]

46. Hagan, M.T.; Menhaj, M.B. Training feedforward networks with the Marquardt algorithm. IEEE Trans. Neural Netw. 1994, 5, 989-993. [CrossRef]

47. El-Bakry, M. Feed forward neural networks modeling for K-P interactions. Chaos Solitons Fractals 2003, 18, 995-1000. [CrossRef]

(C) 2019 by the authors. Licensee MDPI, Basel, Switzerland. This article is an open access article distributed under the terms and conditions of the Creative Commons Attribution (CC BY) license (http://creativecommons.org/licenses/by/4.0/). 